\title{
Developing Baltic cod recruitment models. I. Resolving spatial and temporal dynamics of spawning stock and recruitment for cod, herring, and sprat
}

\author{
Friedrich W. Köster, Christian Möllmann, Stefan Neuenfeldt, Michael A. St. John, \\ Maris Plikshs, and Rüdiger Voss
}

\begin{abstract}
The Baltic Sea comprises a heterogeneous oceanographic environment influencing the spatial and temporal potential for reproductive success of cod (Gadus morhua) and sprat (Sprattus sprattus) in the different spawning basins. Hence, to quantify stock and recruitment dynamics, it is necessary to resolve species-specific regional reproductive success in relation to size, structure, and distribution of the spawning stock. Furthermore, as species and fisheries interactions vary between areas, it is necessary to include these interactions on an area-specific basis. Therefore, areadisaggregated multispecies virtual population analyses (MSVPA) were performed for interacting species cod, herring (Clupea harengus), and sprat in the different subdivisions of the Central Baltic. The MSVPA runs revealed distinct spatial trends in population abundance, spawning biomass, recruitment, and predation-induced mortality. Results, when evaluated with respect to trends in population sizes from research surveys, were similar for the cod and sprat stocks but different for herring. Horizontal distributions from MSVPA runs and research surveys indicate that cod and sprat undergo migrations between basins during different life stages. This is an observation potentially influencing estimates for the different stock components but not affecting the overall stock sizes.
\end{abstract}

Résumé : La mer Baltique est un environnement océanique hétérogène qui influence la variation spatiale et temporelle du succès potentiel de la reproduction chez la Morue franche (Gadus morhua) et le Sprat (Sprattus sprattus) dans les différents bassins de fraye. Pour quantifier les stocks et la dynamique du recrutement, il est donc nécessaire de connaître la relation entre le succès de la reproduction régionale de chaque espèce et la taille, la structure et la répartition du stock des géniteurs. De plus, comme les interactions entre les espèces et la pêche varient d'une région à l'autre, il est nécessaire de les inclure région par région. Des analyses de populations virtuelles plurispécifiques (MSVPA), désagrégées quant à la région, ont été menées sur les espèces en interaction, la Morue, le Hareng (Clupea harengus) et le Sprat dans les différentes subdivisions de la Baltique centrale. Les MSVPA mettent en lumière des structures spatiales distinctes dans la densité de population, la biomasse des géniteurs, le recrutement et la mortalité due à la prédation. Lorsque les résultats sont évalués en tenant compte des tendances dans les tailles des populations obtenues par les inventaires scientifiques, ils sont semblables pour les stocks de Morue et de Sprat mais différents pour le Hareng. Les répartitions horizontales générées par les MSVPA et les inventaires scientifiques montrent que les Morues et les Sprats migrent d'un bassin à l'autre au cours de leur vie. Cette observation peut potentiellement affecter les estimations des différentes composantes des stocks mais non des densités totales des stocks.

[Traduit par la Rédaction]

\section{Introduction}

In the Baltic Sea, the spatial and temporal suitability of the spawning habitats of cod (Gadus morhua) vary dramatically with the oxygen conditions at the depth of incubation of the eggs (Nissling and Westin 1991; Wieland et al. 1994).
As a consequence, the population dynamics of cod exhibit distinct trends in different areas of the Central Baltic (Sparholt and Tomkiewicz 2000), with a corresponding variation in predation pressure on its major prey species, herring (Clupea harengus) and sprat (Sprattus sprattus) (Sparholt 1994). In turn, the population development of these plankti-

Received August 18, 2000. Accepted March 5, 2001. Published on the NRC Research Press Web site at http://cjfas.nrc.ca on July 18, 2001.

$\mathrm{J} 15930$

F.W. Köster, ${ }^{1}$ C. Möllmann, and R. Voss. Institute of Marine Sciences, Düsternbrooker Weg 20, D-24105 Kiel, Germany.

S. Neuenfeldt and M.A. St. John. ${ }^{2}$ Danish Institute for Fisheries Research, Charlottenlund Castle, DK-2920 Charlottenlund, Denmark.

M. Plikshs. Latvian Fisheries Research Institute, Daugavgrivas Street 8, LV-1007 Riga, Latvia.

${ }^{1}$ Corresponding author (e-mail: fkoester@ifm.uni-kiel.de).

${ }^{2}$ Present address: Institute of Hydrobiology and Fisheries Science, Hamburg University, Olbersweg 24, D-22767 Hamburg, Germany. 
Fig. 1. Study area in the Baltic Sea with ICES subdivisions indicated.

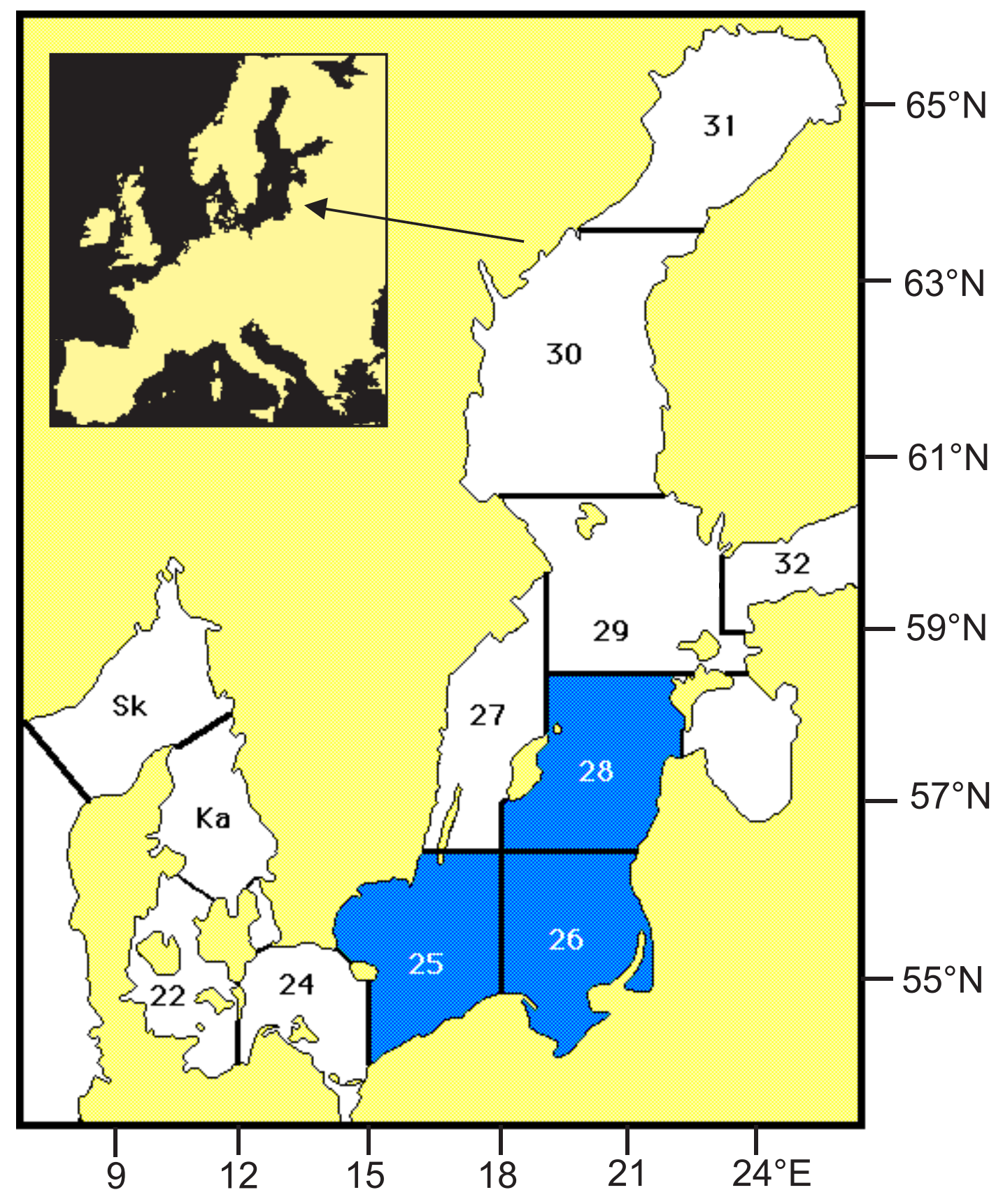

vores determines the predation intensity on early life stages of cod (Köster and Möllmann 2000). Hence, to develop sustainable management strategies for the Central Baltic stocks, assessments and stock projections need to resolve and incorporate the effects of environmental variability and species interactions on reproductive success, in particular the potential for different spawning localities to contribute to recruitment success.

Multispecies virtual population analysis (MSVPA) has been applied addressing the biological interactions between fish stocks in the North Sea (Pope 1991; Stokes 1992) and the Baltic (Sparholt 1991, 1994). Sparre (1991) and Magnusson (1995) presented the theory and methods employed in the MSVPA as well as the underlying assumptions. The model considers predation by specific piscivores on their major fish prey species as biological interactions affecting the population dynamics of the prey stocks. In the Central Baltic, cod, herring, and sprat are the most important fish species and are presently the only species incorporated into the MSVPA (Sparholt 1994). Cod is assumed to be the top predator in the system, exhibiting cannibalistic behaviour, while herring and sprat are treated as prey species. These interactions are based on the analyses of the stomach contents of over $62000 \mathrm{cod}$, the majority of samples originating from International Council for the Exploration of the Sea (ICES) Subdivisions 25, 26, and 28 in the Central Baltic (Fig. 1) collected during 1977-1993. At present, MSVPAs are run for two areas in the Baltic, a Western and a Central Baltic 
component to match the stock units used in the regular stock assessments (Neuenfeldt and Köster 2000), with the Central Baltic component dominating in terms of biomass and abundance (ICES 1998).

Within these two regions, the abundance and biological characteristics of the three species are heterogeneous both spatially (between subdivisions) and temporally (inter- and intra-annually). For example, population sizes of Central Baltic cod, as resolved by international bottom trawl (Sparholt and Tomkiewicz 2000) and ichthyoplankton surveys (Köster et al. 2001), have revealed distinct distributional trends. Furthermore, for cod, substantial differences in weight at age and maturity ogives have been reported for different subdivisions (ICES 1997a; Tomkiewicz et al. 1997). The abundance and characteristics of herring and sprat have also been observed to vary spatially and temporally in the different subdivisions of the Central Baltic (e.g., Ojaveer 1989). The herring stock in the Central Baltic is composed of a number of different spawning components exhibiting variations in spawning period and growth rates as well as meristic, morphometric, and otolith characteristics (e.g., Ojaveer 1981; Parmanne et al. 1994). For sprat, the existence of distinct populations is controversial, as deviations in growth rates observed between subareas have been explained by immigration from the western Baltic and by migration between different basins (Parmanne et al. 1994). However, other authors stated that sprat in the eastern Central Baltic form local populations (Ojaveer 1989), which can be separated, primarily by otolith characteristics (Aps et al. 1981).

In this study, we investigate the feasibility of conducting area-disaggregated MSVPA runs to resolve the dynamics of cod, herring, and sprat subpopulations in the different subdivisions (Fig. 1) corresponding roughly to the Central Baltic basins (Ojaveer and Elken 1995). The major objective of this exercise is to establish cod and sprat spawning population sizes in their different spawning regions, i.e., the Bornholm Basin located in Subdivision 25, the Gdansk Deep in Subdivision 26, and the Gotland Basin in Subdivision 28 (e.g., Ojaveer 1981; Bagge et al. 1994), as characterised by distinct hydrographic conditions (Bagge and Thurow 1993; MacKenzie et al. 2000). This exercise will thereby allow the investigation of regional reproductive success in relation to size and structure of the originating spawning population (Köster et al. 2001).

Resolution of a number of issues is necessary before determining the applicability of the area-disaggregated MSVPA approach. First is the validation of the area-disaggregated MSVPA results with respect to temporal trends in abundance and biomass of cod, herring, and sprat. In order to address this issue, results from trawl and hydroacoustic surveys are compared with the MSVPA output. Secondly, the impact of migration on population abundance may invalidate the approach. This issue is addressed by examining the relative horizontal distributions between subdivisions as determined by area-disaggregated MSVPA and research surveys. Finally, in order to assess the estimates relative to existing information of stock fluctuations, population sizes derived by the MSVPA runs were integrated over Subdivisions 25, 26, and 28 and compared with standard ICES stock assessments (ICES 1998).

\section{Methods}

\section{Area-disaggregated MSVPA parameterisation}

Cod, herring, and sprat in Subdivisions 25, 26, and 28 (Fig. 1) were assumed to be unit stocks composed of age-groups 0-9 for cod and herring and 0-7 for sprat with the oldest age-groups not handled as plus groups. Quarterly catch at age in numbers and weight at age in the catch were utilised for the different subdivisions for 1977-1992 as revised by ICES (1997a) with inputs for 1993-1996 based on national data reported to ICES (1997b). Weight at age in the catch was assumed to be equal to weight at age in the stock, exceptions being weight at age for cod age-groups 0 and 1 . Here, due to size selection by commercial gear, mean values for the whole period were applied as determined by Sparholt (1991). To identify the spawning component of the stocks in the different basins, existing maturity estimates were employed. Maturity ogives for cod in different subdivisions represent averages over 5-year periods available from 1980 onwards for combined sexes (Tomkiewicz et al. 1997). As no data are at present available for the period 1977-1979, estimates from the period 1980-1984 were applied. For herring and sprat stocks, maturity ogives were assumed to be constant over time and the estimates used are those previously employed for these stocks in the Baltic (ICES 1997b).

Estimates of cod predation on herring and sprat as well as of cannibalism are based on quarterly cod stomach content data by subdivision as revised in ICES (1997a). Average age-specific quarterly consumption rates were estimated by subdivision as described in ICES $(1999 a)$. The residual natural mortality rate was assumed to be $0.2 \cdot$ year $^{-1}$, equally distributed over quarters, corresponding to standard MSVPA runs in the Baltic (Sparholt 1991). Suitability coefficients of prey species age-groups as food of specific predator age-groups (Sparre 1991) were estimated according to the standard suitability submodel implemented in the Baltic MSVPA (ICES 1997a). The tuning of the MSVPAs was performed by iteratively running extended survivor analyses (Shepherd 1999) and MSVPAs exchanging updated terminal fishing and predation mortalities until convergence was achieved (Neuenfeldt and Köster 2000). Abundance indices utilised for tuning originated from the international bottom trawl survey directed to cod, performed annually in February-March (Sparholt and Tomkiewicz 2000), and the international hydroacoustic survey directed to herring and sprat, conducted annually in September-October (ICES 1998).

\section{Validation of area-disaggregated MSVPA results}

To assess the feasibility of employing the area-disaggregated MSVPA for resolving temporal trends of stock abundance in the different basins, results from the model are compared with trawl and hydroacoustic surveys estimates. Data from these sources fall into two categories: those being data used to tune the areadisaggregated MSVPA, thus nonindependent, and data not employed for tuning purposes. The international surveys utilised for tuning, although having an impact on the MSVPA results during the later part of the time series, have a reduced effect on the outputs back in time. This feature makes these data valid for a comparison of trends for a major part of the time series.

As a second mode of validation, independent population size indices are available from other research surveys, e.g., directed to spawning concentrations and young fish abundance. These indices, although independent, are typically not focused on monitoring population sizes and hence are of a lower quality than the nonindependent data designed for this task. For the purposes of validation, however, these sources are applicable for examining trends in abundance.

The third method of validation involves the temporal coherence of population abundance and structure in the various basins. The comparison of relative horizontal distributions and corresponding age structures of the different subpopulations from area- 
Fig. 2. SSB (second quarter) of $(a)$ cod, $(b)$ herring, and $(c)$ sprat and recruitment at age 1 (beginning of the year) of $(d)$ cod, $(e)$ herring, and $(f)$ sprat from area-disaggregated MSVPA in different subdivisions of the Central Baltic Sea (solid circles, Subdivision 25; open circles, Subdivision 26; triangles, Subdivision 28).

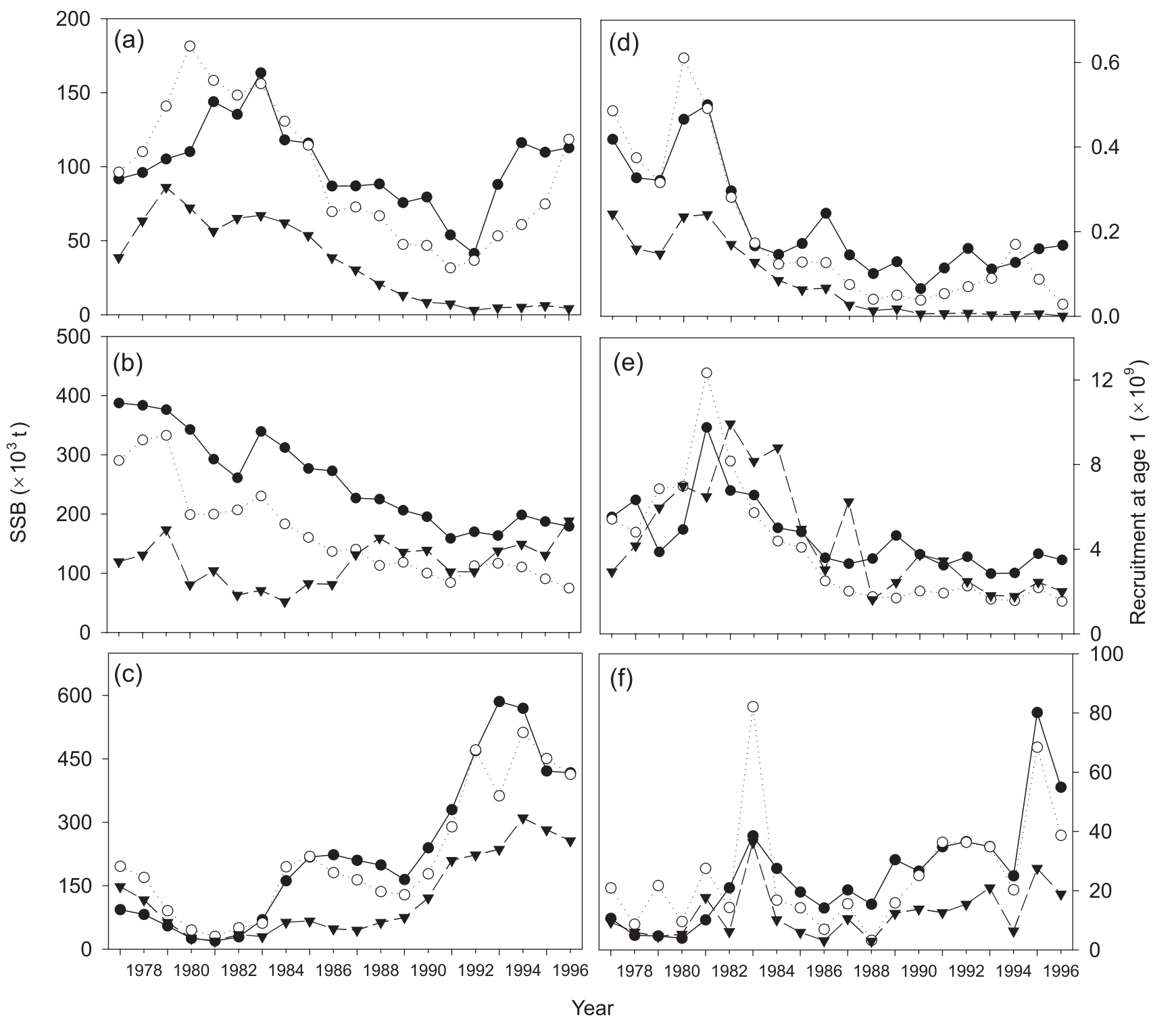

disaggregated MSVPA runs and corresponding research surveys will validate the suitability of the approach regarding age-specific migration between subdivisions.

Finally, spawning stock sizes and recruitment derived by the area-disaggregated MSVPAs were summed over Subdivisions 25, 26, and 28 and compared with corresponding estimates from the standard stock assessment for the Central Baltic. These are comparable, as the standard assessment utilises predation mortalities from area-aggregated MSVPAs as input. This exercise resolves whether the approach of running a suite of independent MSVPAs generates robust results when compared with the best available information on stock development.

\section{Results}

\section{Output from area-disaggregated MSVPA runs}

\section{Spawning populations}

Spawning stock biomass (SSB) values for cod, herring, and sprat in the different subdivisions from the areadisaggregated MSVPA runs are presented in Fig. 2 and Appendix Table A1. The Central Baltic cod stock displayed a substantial decrease in SSB in all three areas from 1983 onwards. The SSB increased again in the early 1990s in Subdivisions 25 and 26 due to enhanced reproductive success and a reduction in fishing mortality; however, no recovery was evident in Subdivision 28.

The herring SSB in Subdivisions 25 and 26 showed a more or less continuous decline to less than half of the original level from the beginning of the time series until the early 1990s. Thereafter, the SSB stabilised, being substantially lower in Subdivision 26. The SSB in Subdivision 28 exhibited an increase in stock size in the second half of the time series, reaching spawning stock sizes similar to those in Subdivision 25 in most recent years.

The SSB of sprat in Subdivisions 25 and 26 showed a rather similar time trend, with an increase from very low 
Fig. 3. Annual predation mortality rates of cod, herring, and sprat $(a)$ age-group $0,(b)$ age-group 1, and $(c)$ cod age-group 2, herring age-group 2-7, and sprat age-group 2-5 from area-disaggregated MSVPA in different subdivisions of the Central Baltic Sea (solid circles, Subdivision 25; open circles, Subdivision 26; triangles, Subdivision 28). Note that predation mortality of the 0-group refers to the third and fourth quarters.

(a)

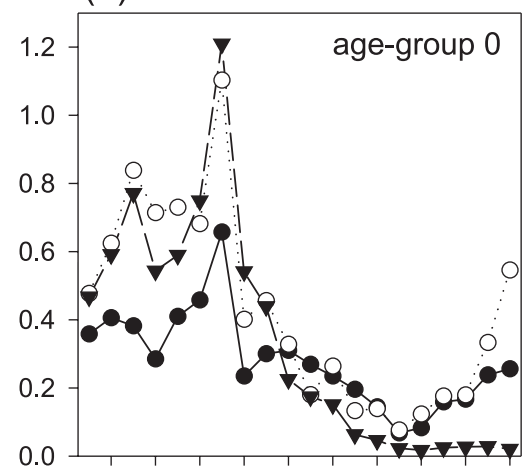

(b)

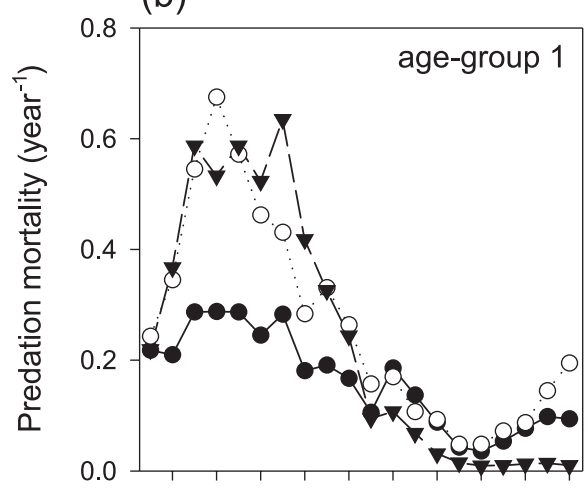

(c)

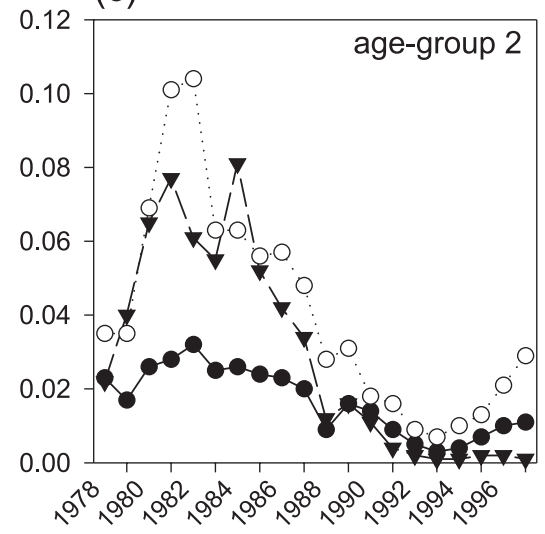

Herring
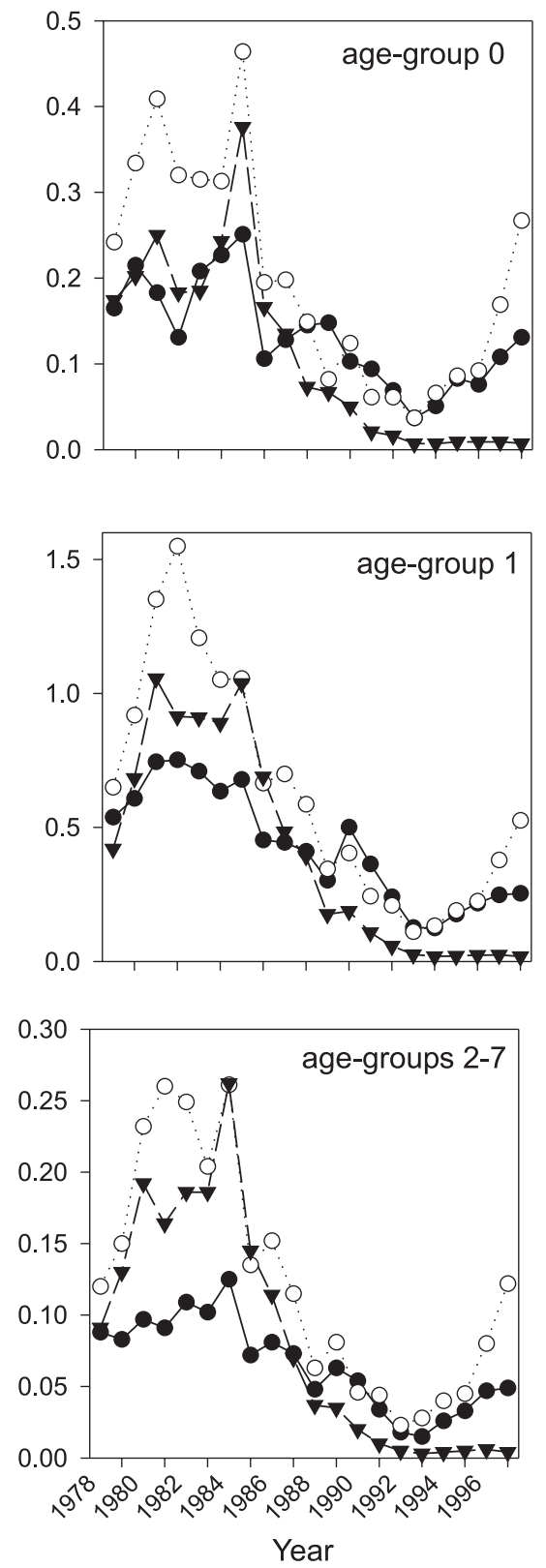

Sprat
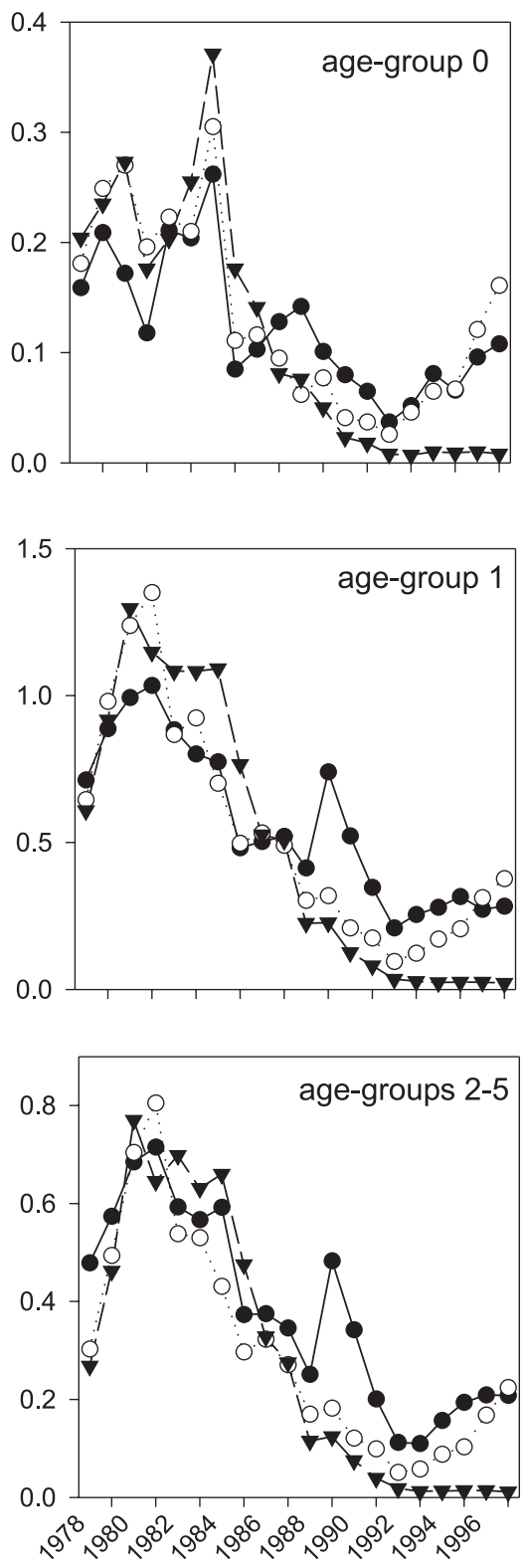

levels in the beginning of the 1980 s to stable intermediate values in the second half of the decade. In the beginning of the 1990s, a substantial increase in the spawning stock is estimated for both areas. In Subdivision 28, fluctuations in the SSB were much less pronounced; however, the general trend was rather similar to that in Subdivisions 25 and 26.

\section{Recruitment}

Estimated recruitment of cod, herring, and sprat at age 1 for the different subdivisions is displayed in Fig. 2 and Appendix Table A1. A declining trend in cod recruitment is evident in the 1980s for all areas. The abundance of 1-group cod was estimated to be lowest in Subdivision 28 throughout the time series, with extremely low estimates of recruitment in this subdivision since 1990. During the second half of the time series, cod recruitment was estimated to be highest in Subdivision 25 (with the exception of the 1993 year-class). An increase in recruitment from 1990 to 1994 is visible for Subdivision 26, followed by a decline in recent years.

Trends of herring recruitment to age 1 are in general similar in all subareas, with a decline throughout the decade from maximum values during the beginning of the 1980s. Thereafter, recruitment stabilised in all areas, being highest in Subdivision 25 and lowest in Subdivision 26. 
Sprat recruitment was variable during the early part of the time series, with an outstanding year-class evidenced in 1982. During this period, recruitment in Subdivision 26 was in general highest. Since 1982, recruitment in Subdivision 28 was estimated to be the lowest, with a less pronounced increase in reproductive success than in the other basins after the late 1980s. Recruitment success in Subdivisions 25 and 26 has shown a similar trend since 1990, first with intermediate and finally with high recruitment.

\section{Predation mortality}

A substantial difference in cod cannibalism rates between areas is apparent (Fig. 3), with the lowest predation on cod estimated for 1978-1985 in Subdivision 25. Furthermore, age-specific differences in predation mortality are pronounced, with cannibalism rates on 0-group cod being considerably higher than on 1-group cod. Predation on 2-group cod was in general low, i.e., less than $50 \%$ of the applied residual mortality of 0.2 . In Subdivision 28, cannibalism rates declined from maximum values in 1983 to extremely low values in the 1990s.

Predation rates of cod on herring (Fig. 3) were highest in Subdivision 26 in the beginning and at the end of the time series, independent of prey age. In all areas, predation mortality rates declined throughout the 1980s to lowest levels in early 1990s, with a subsequent increase in most recent years in Subdivision 25 and 26, while predation in Subdivision 28 remained rather low. Estimated predation mortality rates were in general highest for 1-group herring, intermediate for 0-group herring, and comparatively low for older herring.

Maximum predation pressure on 0-group sprat occurred in 1983 and on older age-groups 3-4 years earlier (Fig. 3). Independent of the prey age, a decrease in predation mortality occurred until 1991, with a subsequent increase in recent years in Subdivisions 25 and 26. Cod predation on juvenile sprat was of a similar magnitude to that estimated for herring, while predation mortality rates of adult sprat were considerably higher than for adult herring.

\section{Validation of area-disaggregated MSVPA results}

Validation employing trawl and hydroacoustic surveys used for MSVPA tuning

Significant linear relationships were obtained between areadisaggregated MSVPA estimates of cod population size (age-group 2+) (Appendix Table A1) and abundance indices based on bottom trawl surveys (Appendix Table A2) in all three subareas (Fig. 4), with the lowest $r^{2}$ values observed in Subdivision $25\left(r^{2}=0.64\right)$, intermediate in Subdivision 26 $\left(r^{2}=0.69\right)$, and highest in Subdivision $28\left(r^{2}=0.80\right)$. Intercepts were significant for Subdivisions 26 and $28(p=0.039$ and 0.041$)$ but not in Subdivision $25(p=0.052)$. Large interannual variability was observed in the international trawl survey in Subdivision 25 in 1980-1982 and 19851987, causing large deviations between observed and modelled population abundance. Similarly, in Subdivision 26, considerable deviations occurred in the beginning of the time series, with a high trawl survey abundance index in 1982 and a relatively low one in 1983. Interestingly, in Subdivision 28, the 1983 survey revealed the highest abundance indices on record, potentially indicating a shift in distribution compared with 1982 and subsequent years. Apart from this observation, evidence of interannual shifts in distribution between different subareas is not apparent. Correlating the age-specific abundance values obtained from the areadisaggregated MSVPA runs against corresponding indices from the trawl survey revealed a dome-shaped pattern of $r^{2}$ values with age, being lowest in the oldest age-groups. This might indicate tuning problems encountered for these agegroups, while the decreasing fit in younger age-groups can be explained mainly by trawl selectivity. Cod recruitment estimates at age 1 derived by area-disaggregated MSVPA runs (Appendix Table A1) were nevertheless significantly correlated with abundance indices from the survey (Appendix Table A3), with highest variability in Subdivision 25 (Table 1). Here, an especially low abundance index of the 1979 year-class in the 1980 survey does not coincide with high recruitment estimated by the area-disaggregated MSVPA. Excluding this year-class from the correlation improved the relationship between both recruitment estimates considerably $\left(r^{2}=0.60\right)$.

In contrast with cod, correlation between abundance estimates of herring from area-disaggregated MSVPA runs (Appendix Table A1) and hydroacoustic surveys (Appendix Table A2) revealed no significant relationships for any of the subdivisions (Fig. 4).

For sprat, the comparison between international hydroacoustic survey results (Appendix Table A2) and areadisaggregated MSVPA output (Appendix Table A1) revealed trends similar to those observed for cod (Fig. 4), also with lowest $r^{2}$ values in Subdivision $25\left(r^{2}=0.59\right)$ and highest in Subdivision $28\left(r^{2}=0.80\right)$. The increase in population size in the 1990s observed in the MSVPA estimates for Subdivision 25 is less pronounced in the hydroacoustic surveys. In particular, the survey estimate obtained in 1992 appears to be rather low. Due to technical and area coverage problems, the hydroacoustic surveys in 1992 and 1993 (the latter omitted here) have been suggested to be the most unreliable in the present time series and are in fact excluded from regular assessment runs (ICES 1997b). In Subdivision 28, contrary to Subdivision 25, the increase in population size in recent years is more pronounced in the hydroacoustic survey than in the area-disaggregated MSVPA. A similar comparison for sprat recruitment at age 1 (Appendix Tables A1 and A3) revealed significant correlations for all subareas, with highest $r^{2}$ values in Subdivision 25 and lowest in Subdivision 28 (Table 1). In the latter area as well as in Subdivision 26, large deviations occurred for the 1982 year-class, with the MSVPA estimates being significantly higher. Excluding this year from the correlation increased the $r^{2}$ values considerably (0.65 in Subdivision 26 and 0.79 in Subdivision 28). Thus, recruitment of the 1982 year-class appears to be severely overestimated by the area-disaggregated MSVPA, while in general, hydroacoustic- and MSVPA-derived recruitment estimates are in good agreement.

\section{Validation employing independent research surveys}

Validation of the area-disaggregated MSVPA estimates for cod was performed against Latvian bottom trawl surveys conducted in Subdivisions 26 and 28 in January and NovemberDecember during 1976-1991 (Appendix Table A2). These estimates of age-group $3+\operatorname{cod}$ abundance were significantly correlated with the corresponding area-disaggregated MSVPA 
Fig. 4. Population sizes of cod (age-group 2+), herring (age-group 1+), and sprat (age-group 1+) derived by area-disaggregated MSVPA at the time of survey versus abundance indices from tuning fleets. (a) Subdivision 25; (b) Subdivision 26; (c) Subdivision 28. The coefficient of determination $\left(r^{2}\right)$ is from a linear regression model, allowing for an intercept. BITS, Baltic international trawl survey.

(a)

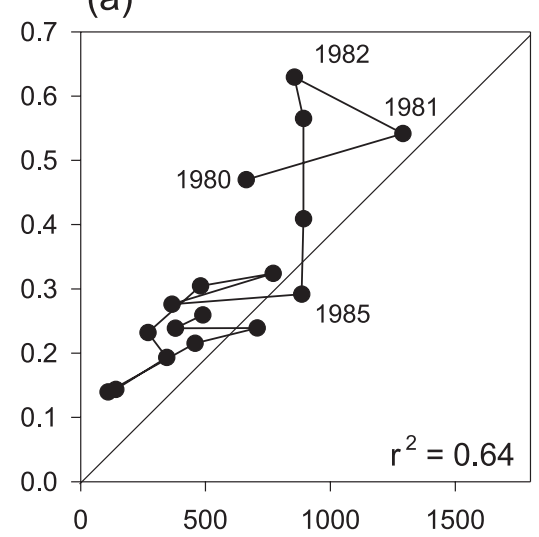

(b)

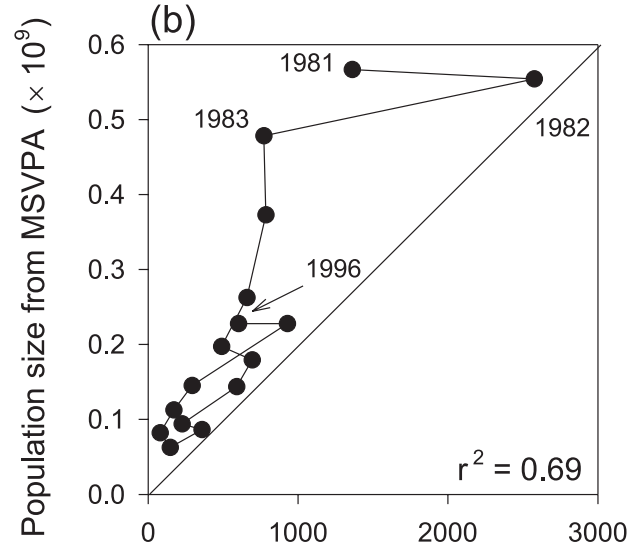

(c)

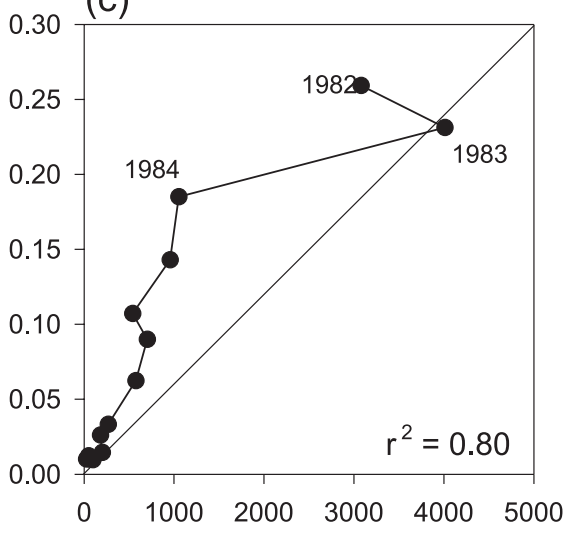

Abundance index from BITS survey $\left(\cdot h^{-1}\right)$
Herring
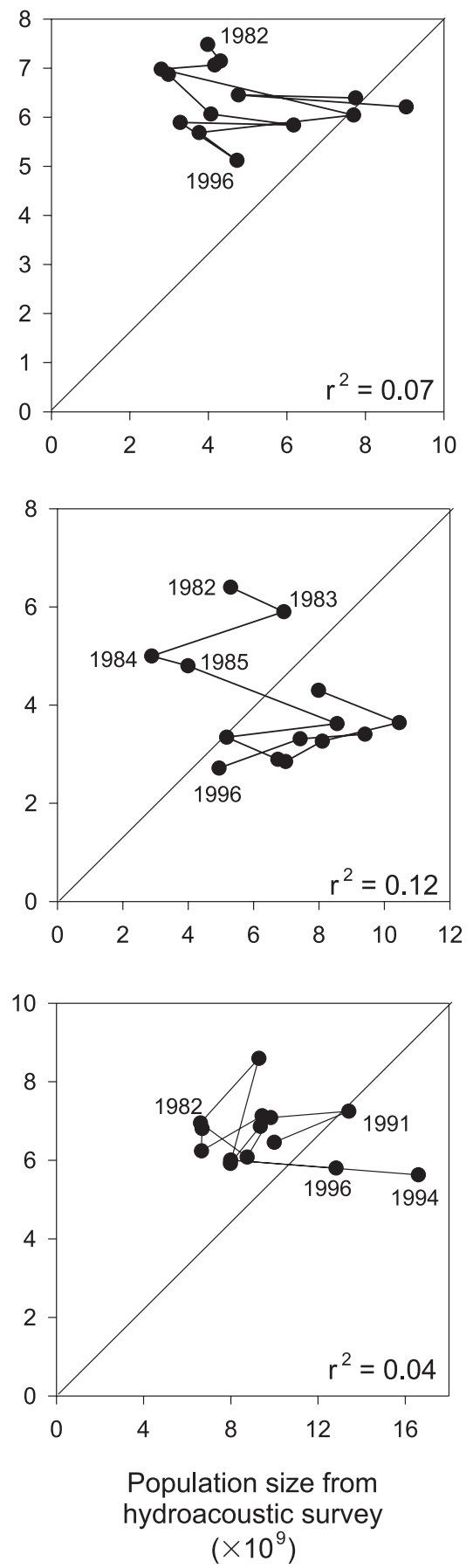

Sprat
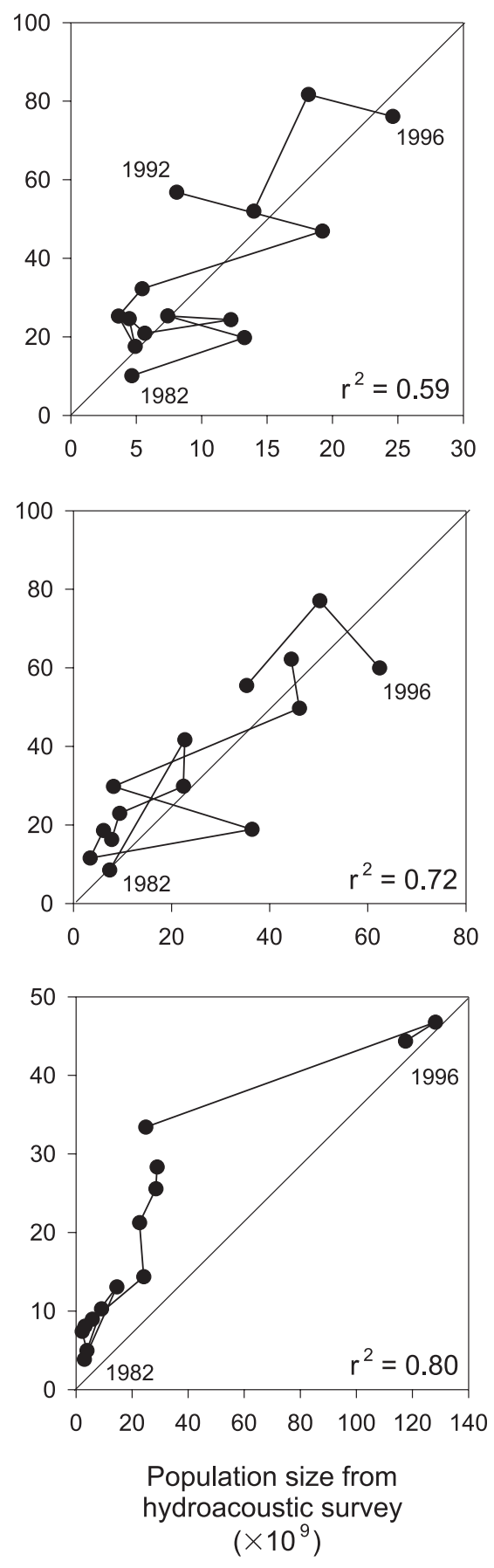

output (Fig. 5), with $r^{2}$ values ranging from 0.52 to 0.90 . Despite these significant relationships, a number of noteworthy deviations were evident. Outstandingly high abundances of $3+\operatorname{cod}$ in Subdivision 28 were encountered in the trawl surveys in January 1983, a result not reflected in the MSVPA estimates. In Subdivision 26, a reverse situation was encountered, with comparatively low catch rates in January and November-December 1983 as compared with high population abundance estimated by the MSVPA. These results may indicate an anomalous distribution of the stock in 1983 as in the previous section identified by the international bottom trawl survey.

Further corroborative results come from Latvian demersal trawl surveys on cod spawning concentrations in the Gotland Basin (Uzars et al. 1991). These show a decline in biomass indices of $84 \%$ during the period 1980-1989, a result corre- 
Table 1. Linear regressions performed to validate cod and sprat recruitment (age-group 1) from area-disaggregated MSVPA (dependent variable) (numbers) using results from the international bottom trawl survey for cod $\left(\right.$ no. $\left.\cdot h^{-1}\right)$ and the international hydroacoustic survey for sprat (numbers), parameter estimates, and their significance level and $r^{2}$ value.

\begin{tabular}{|c|c|c|c|c|c|}
\hline Subdivision & Year-classes & Parameter & $\begin{array}{l}\text { Parameter } \\
\text { estimate }\end{array}$ & $p$ & $r^{2}$ \\
\hline \multicolumn{6}{|l|}{ Cod } \\
\hline \multirow[t]{2}{*}{25} & 1979-1995 & Slope & $6.2329 \times 10^{6}$ & 0.015 & 0.34 \\
\hline & & Intercept & $1.4396 \times 10^{8}$ & $<0.001$ & \\
\hline \multirow[t]{2}{*}{26} & 1980-1995 & Slope & $3.2003 \times 10^{6}$ & $<0.001$ & 0.73 \\
\hline & & Intercept & $9.1831 \times 10^{7}$ & $<0.001$ & \\
\hline \multirow[t]{2}{*}{28} & 1981-1995 & Slope & $8.3191 \times 10^{6}$ & $<0.001$ & 0.88 \\
\hline & & Intercept & 98953 & $<0.001$ & \\
\hline \multicolumn{6}{|l|}{ Sprat } \\
\hline \multirow[t]{2}{*}{25} & 1981-1995 & Slope & 5.4102 & $<0.001$ & 0.68 \\
\hline & & Intercept & $2.1162 \times 10^{10}$ & $<0.001$ & \\
\hline \multirow[t]{2}{*}{26} & 1981-1995 & Slope & 1.3676 & 0.012 & 0.42 \\
\hline & & Intercept & $1.1497 \times 10^{10}$ & 0.146 & \\
\hline \multirow[t]{2}{*}{28} & 1981-1995 & Slope & 0.2798 & 0.002 & 0.35 \\
\hline & & Intercept & $9.8700 \times 10^{10}$ & 0.024 & \\
\hline
\end{tabular}

Fig. 5. Population sizes of cod (age-group 3+) derived by area-disaggregated MSVPA versus abundance indices from the Latvian bottom trawl survey in Subdivisions (SD) 26 and 28. (a) January; (b) November-December. The coefficient of determination $\left(r^{2}\right)$ is from a linear regression model, allowing for an intercept.

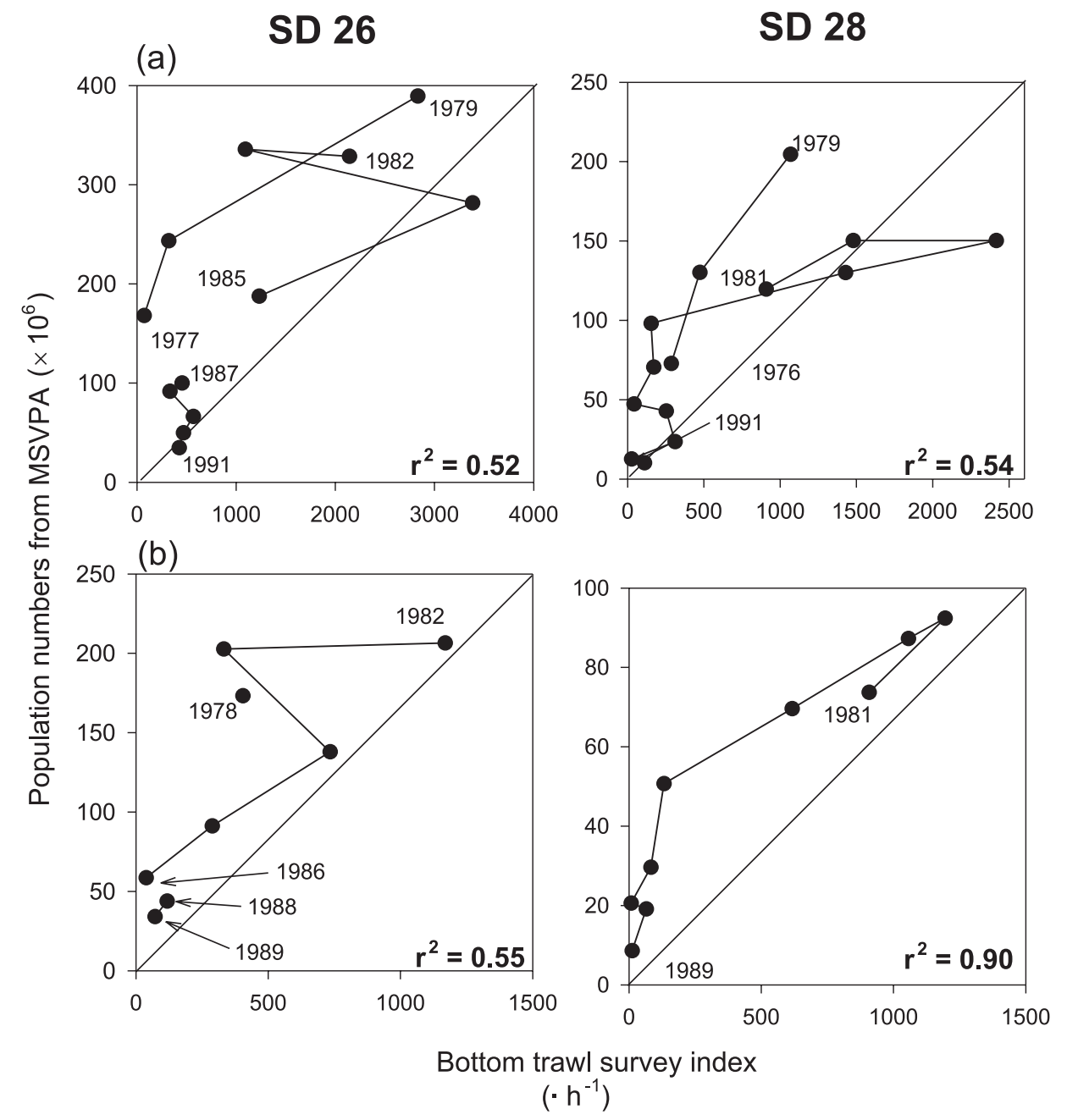


Table 2. Comparison of sprat biomass estimates (age-group 1+) (kt) in different subdivisions (SD) as derived from hydroacoustic surveys in May-June and area-disaggregated MSVPA (second quarter).

\begin{tabular}{|c|c|c|c|c|c|c|}
\hline \multirow[b]{2}{*}{ Year } & \multicolumn{2}{|l|}{ SD 25} & \multicolumn{2}{|l|}{ SD 26} & \multicolumn{2}{|l|}{ SD 28} \\
\hline & Survey & MSVPA & Survey & MSVPA & Survey & MSVPA \\
\hline 1979 & 161 & 56 & 118 & 104 & 162 & 49 \\
\hline 1981 & 68 & 73 & 76 & 101 & 41 & 51 \\
\hline 1982 & 149 & 143 & 70 & 83 & 110 & 40 \\
\hline 1984 & 159 & 341 & 120 & 319 & 147 & 92 \\
\hline 1985 & & & 152 & 285 & 173 & 84 \\
\hline 1986 & 153 & 295 & 128 & 215 & 165 & 63 \\
\hline 1995 & 465 & 722 & 560 & 737 & 440 & 448 \\
\hline
\end{tabular}

Note: An empty cell indicates that a reliable survey was not conducted during that period.

sponding to a similar decline of the SSB derived by the areadisaggregated MSVPA for the same period. Catch rates from pelagic trawl surveys covering the Bornholm Basin at different times of the spawning season revealed on average a $53 \%$ reduction in abundance of sexually mature cod from 1995 to 1996 (ICES 1999b), a trend that is not obvious from the area-disaggregated MSVPA. Comparing the daily egg production at peak spawning time as derived by ichthyoplankton surveys with corresponding potential annual egg production from 1986 to 1996 (Köster et al. 2001) revealed maximum egg production by both methods in the Bornholm Basin in 1994 and 1995. In 1996, a large potential egg production (only 5\% lower than the maximum in 1994) is contrasted by a $46 \%$ lower egg production as obtained from the ichthyoplankton survey. This indicates an overestimation of the most recent cod population size obtained by the areadisaggregated MSVPA for Subdivision 25.

Unfortunately, hydroacoustic surveys by the former GDR/USSR conducted in May-June 1979-1986 (Sjöstrand 1989) are not representative of the abundance of herring. The majority of the spring-spawning herring aggregate outside the survey area on their spawning grounds during this period (e.g., Aro 1989; Parmanne et al. 1994), making these observations unreliable for estimating abundance and distribution. Other independent survey information, e.g., the Polish young fish survey, either showed high interannual variability (ICES 1998) or did not cover comparable areas or sufficient time periods (Sjöstrand 1989). Thus, the available independent data on herring abundance appear to be insufficient for validation of the area-disaggregated MSVPA results.

Validation of area-disaggregated MSVPA derived biomass values of sprat were performed using above-mentioned hydroacoustic surveys (Table 2) conducted in May-June 19791986 (data compiled by Sjöstrand 1989) as well as Danish and Russian hydroacoustic surveys conducted in May-June 1995 (J. Tomkiewicz, Institute of Marine Sciences, Kiel, Germany, personal communication; T.G. Vasilieva, Atlantic Scientific Research Institute of Marine Fisheries and Oceanography, Kaliningrad, Russia, personal communication). The correlation between area-disaggregated MSVPA output and hydroacoustic survey results was high in all subdivisions $\left(r^{2}=0.83\right.$ to 0.91$)$, driven mainly by the increase in stock biomass from the mid-1980s to 1995 .

\section{Population spatial dynamics}

In order to validate the spatial distribution of adult cod in the Central Baltic, the area-specific relative abundance of age-group 3+ from bottom trawl surveys in February-March (Sparholt and Tomkiewicz 2000) is plotted against the relative population abundance from the area-disaggregated MSVPAs (Fig. 6). In Subdivision 26, the population remained stable throughout the time period, with the highest abundance observed in both the trawl survey and MSVPA estimates in 1996. In Subdivision 25, the proportions estimated by the MSVPA were in general higher than that observed in the trawl surveys, whereas in Subdivision 28, the MSVPA estimates were in general lower. Within the latter area, a clear time trend of decreasing importance of the stock component is indicated by both data sources, with recent years being similarly low in the area-disaggregated MSVPA and trawl survey results.

Cod recruits (age-group 1) showed a different distribution pattern than did adult cod. Highest proportions were encountered by the trawl survey in Subdivision 26, while the MSVPA estimated intermediate proportions (Fig. 6). On the contrary, in Subdivision 25, the MSVPA-derived recruitment is in general high and the corresponding fractions in the trawl surveys are comparatively low, with a time trend of increasing importance of the area determined by the former but not by the latter. For Subdivision 28, independent of the method, rather similar low proportions were calculated, especially in recent years. The distribution pattern of agegroup 2 by the area-disaggregated MSVPA changed only slightly from that of age-group 1. However, in the trawl survey, considerable changes with age were observed, with increased proportions in Subdivisions 25 and 28 and decreased proportions in Subdivision 26.

The higher fraction of the cod stock derived by the trawl surveys in Subdivision 28 and a lower fraction in Subdivision 25 may be interpreted as a spawning migration from the Gotland Basin to the Bornholm Basin taking place after the bottom trawl survey is performed in the first quarter. These migrations have been previously described (Lablaika and Lishev 1961).

The distribution pattern from the trawl survey changes with age, i.e., recruits of age-group 1 concentrate in Subdivision 26. A biological explanation for this dislocation relative to the area-disaggregated MSVPA results may be a drift of larvae and pelagic juveniles out of the Bornholm Basin into the neighbouring subdivision, which has been identified through the application of hydrodynamic models (Voss et al. 1999; Hinrichsen et al. 2001). The change in relative distribution of age-group 2 indicates either a higher mortality of juveniles in Subdivision 26, not accounted for in the MSVPA, or a movement out of the area. In fact, an analysis of catch rates obtained from Latvian trawl surveys conducted at different times of the year in the Gotland Basin (see above) revealed indications of an expansion of juvenile cod into the Gotland Basin from southern areas.

The relative distribution of herring obtained by hydroacoustic surveys in September-October and that of the area- 
Fig. 6. Relative horizontal distributions of total cod abundance indices (age-groups 3+, 1, and 2) from the Baltic international trawl survey versus corresponding relative distributions estimated by area-disaggregated MSVPA. (a) Subdivision 25; (b) Subdivision 26; (c) Subdivision 28 .

(a)
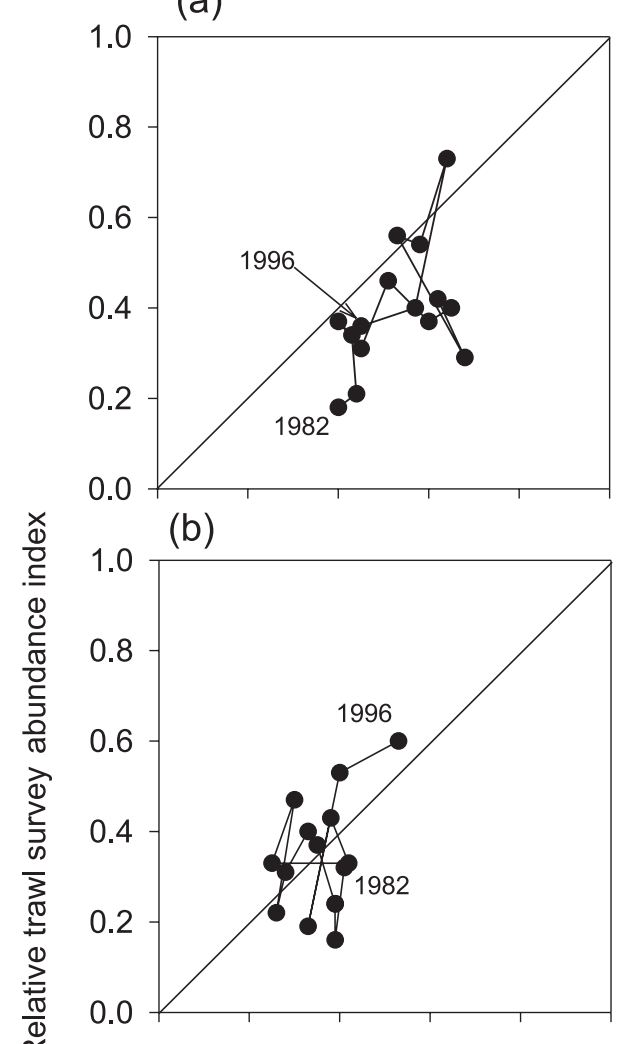

(c)

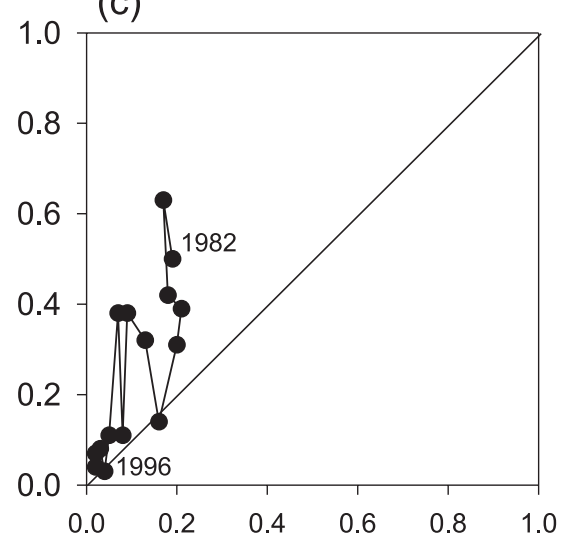

age-group 1
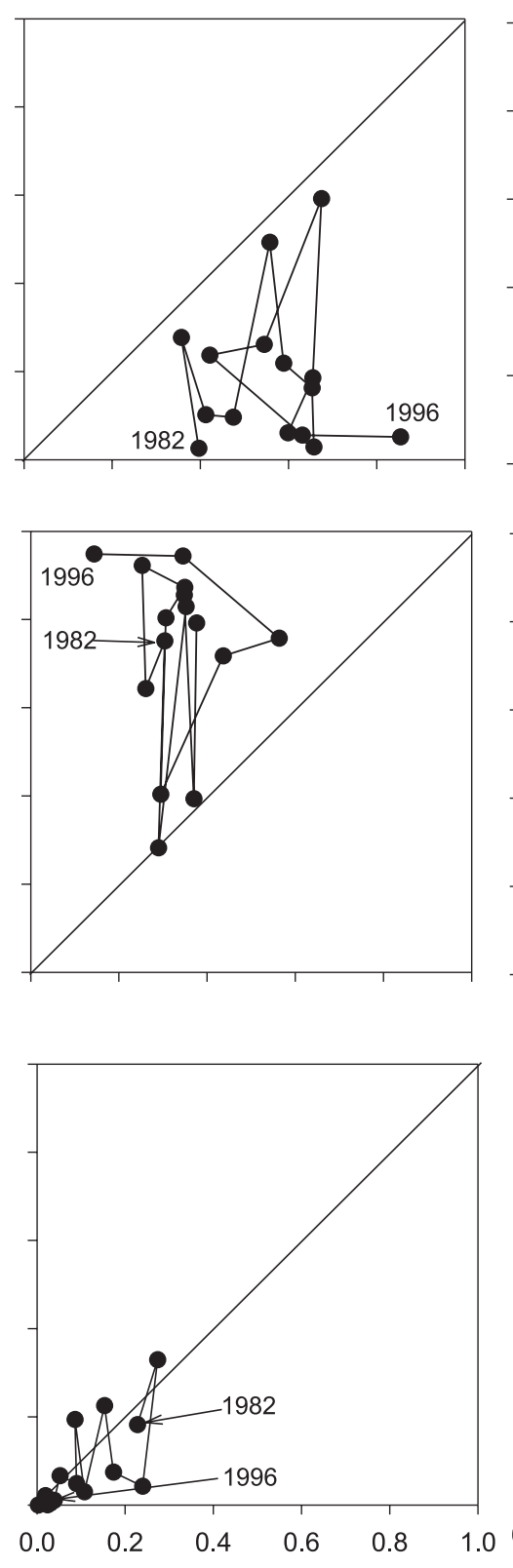

age-group 2
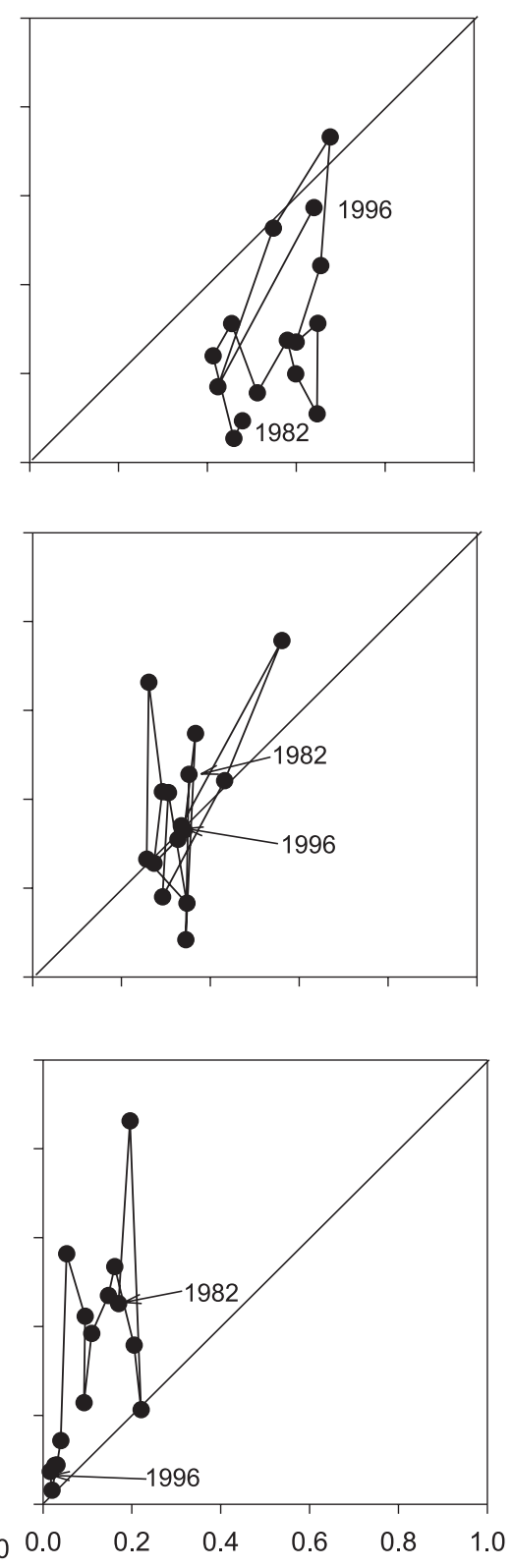

Relative MSVPA population size

disaggregated MSVPA match on average for Subdivision 28, whereas the fraction inhabiting Subdivision 25 estimated by the MSVPA was slightly higher (Fig. 7). Pronounced long-term changes in the relative distribution of the herring populations were not obvious in any of the time series. Although not commonly agreed, it has been argued (e.g., Ojaveer 1989) that there exist three distinct herring groups in the Baltic, the open sea and the coastal spring-spawning herring as well as the autumn-spawning herring, represented by various independent stocks, showing different migration patterns. Additionally, the intensity of these migrations depends on environmental conditions and food supply (Parmanne et al. 1994). Hence, due to this complex stock structure and the migratory behaviour of herring within and between subdivisions (e.g., Aro 1989; Ojaveer 1989), an evaluation of the obtained relative distribution patterns from the area-disaggregated MSVPA is extremely difficult.

When repeating the exercise for sprat using the international hydroacoustic survey of September-October, a picture similar to that for cod is obtained. Higher proportions are es- 
Fig. 7. Relative horizontal distributions of total herring and sprat abundance (age-group 1+) from the international hydroacoustic survey versus corresponding relative distributions derived by area-disaggregated MSVPA. (a) Subdivision 25; (b) Subdivision 26; (c) Subdivision 28.

(a)

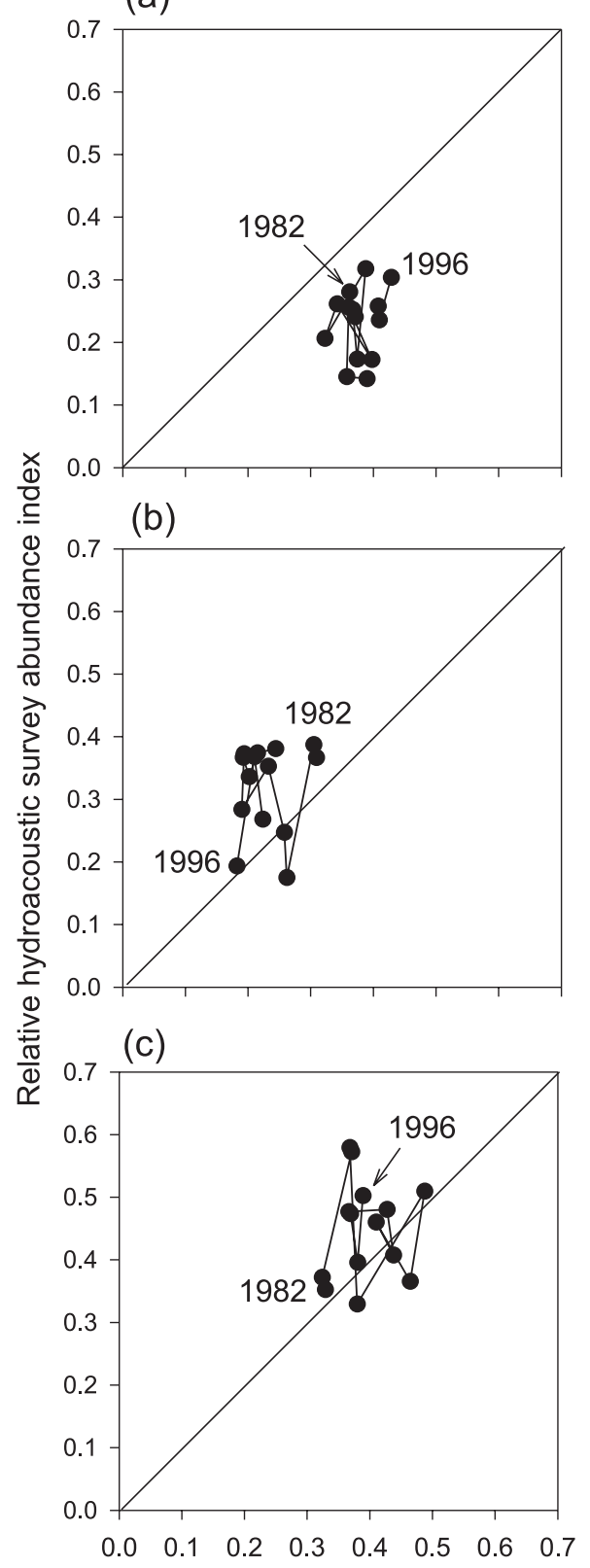

Sprat
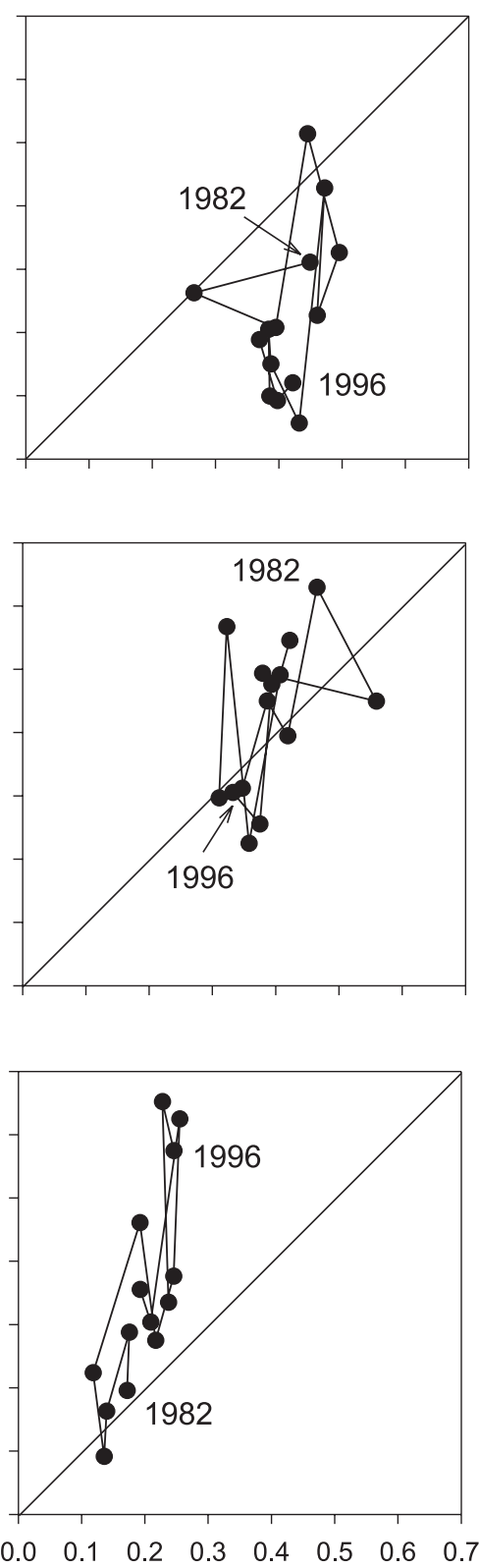

Relative MSVPA population size

timated for Subdivision 25 by the MSVPA and lower abundance in Subdivision 28, with increasing deviations with time, and on average similar fractions in Subdivision 26 (Fig. 7). A comparison of the average distribution patterns obtained from both data series with corresponding values derived by hydroacoustic surveys in May-June 1979-1986 (ICES 1999a) shows that the similarity to the areadisaggregated MSVPA output is considerably greater than to the hydroacoustic survey in autumn. The former allocated on average $37 \%$ of the stock to Subdivision 25 and $42 \%$ to Subdivision 26. The survey in May-June revealed a correspond- ing fraction of the stock inhabiting Subdivision 25 and on average similar population levels in both eastern areas. In contrast, the hydroacoustic survey in September-October identified the highest population sizes to be in Subdivision $26(52 \%)$ and considerably lower fractions of the stock in Subdivision $25(26 \%)$. This could be interpreted as spawning migrations from Subdivision 26 into the Bornholm Basin and the central Gotland Basin. However, when interpreting the encountered deviations in relative distributions, an exchange between noncovered Subdivisions 27 and 29 and the study area must be considered. Additionally, sprat from the 
western Baltic migrate to some extent to the Bornholm Basin for spawning (Aro 1989; Parmanne et al. 1994).

\section{Comparison of standard stock assessment and area-} disaggregated MSVPA results

Standard assessment results for the Central Baltic cod stock (Subdivisions 25-32), the Central Baltic herring stock (Subdivisions 25-29 and 32, including the Gulf of Riga), and the Baltic sprat stock (Subdivisions 22-32) (ICES 1998) allow validation of the output of the area-disaggregated MSVPA (summed over Subdivisions 25, 26, and 28). The standard assessment utilises area-aggregated MSVPA derived predation mortalities as input and is thus comparable with the integrated results obtained by the area-disaggregated MSVPAs. However, stock units for all three species are not the same, as the regular assessment also includes at least Subdivisions 27,29 , and 32 . The major part of the cod catch (90-98\%) is nevertheless taken in the areas covered by the present study (Sparholt and Tomkiewicz 2000).

Herring population estimates for Subdivisions 25-28 can be obtained from standard assessment results (ICES 1998) encompassing Subdivisions 25-29 and 32, when subtracting stock estimates for Subdivisions 29 and 32 determined by ICES (1998). However, Subdivision 27 is still included as an area that sustains a substantial herring fishery and for which the international hydroacoustic survey on average estimates $21 \%$ of the entire population in the Central Baltic.

The standard assessment of sprat treats the entire Baltic as one stock unit. To account for sprat in the western Baltic (Subdivisions 22-24), population estimates derived by an earlier MSVPA (ICES 1997a) were subtracted from the estimates for the entire Baltic. Subdivisions 25, 26, and 28 covered in the present study sustain the major part of the sprat catch in the Baltic (79-83\% in recent years). Nevertheless, the area-disaggregated MSVPA population sizes should to a certain degree underestimate the Central Baltic sprat stock compared with the standard assessment (excluding Subdivisions 22-24), as Subdivisions 27, 29, and 32 are still not included.

Standard assessment and area-disaggregated MSVPA derived estimates of cod SSB show a similar development from 1986 to 1995 (Fig. 8). The standard assessment estimates are in general slightly higher, due to the incomplete area coverage by our disaggregated multispecies assessment. A relatively large discrepancy occurred in 1996, with the regular assessment estimate being substantially lower. This result confirms the overestimation by the area-disaggregated MSVPA of the population size in Subdivision 25 in recent years (described above). In the first part of the time series, considerably higher SSB values were estimated by the standard assessment. This cannot be explained by the lack of inclusion of Subdivisions 27, 29, and 32 in the present areadisaggregated MSVPA runs. Other factors, e.g., differences in the recompiled catch and especially weight at age data (see below), obviously contribute to this deviation.

For herring, the trends in SSB estimates from standard assessment and area-disaggregated MSVPA were rather similar, with a less rapid decline in the stock predicted by the latter (Fig. 8). The difference between the estimates from Subdivisions 25-28 and the area-disaggregated MSVPA output are higher than expected from the lack of area coverage, which is caused by deviations in the revised and the standard assessment catch at age database (ICES 1999a).

Standard assessment and area-disaggregated MSVPA estimates for sprat SSB are relatively similar throughout the entire time series (Fig. 8). Until 1983, the standard assessment SSBs are higher than the corresponding multispecies estimates; this could be expected due to the differences in area coverage. However, since 1984 the area-disaggregated MSVPA derived spawning stocks are in general slightly higher.

Cod recruitment estimates derived by both assessments (age-group 2) were similar throughout the time series (Fig. 9). This clearly demonstrates that the large deviations encountered in the SSB early in the time series are generated to a large extend by deviations in weight at age in the stock. These are set as constant in the regular assessment before 1983.

For herring, standard assessments give an impression with respect to recruitment (age-group 1) development similar to our multispecies assessment until the mid-1980s but show increasing differences afterwards (Fig. 9). As expected, recruitment values generated by the area-disaggregated MSVPA runs were in general lower. However, especially in the beginning of the time series, the deviation was less than expected. This indicates that the major changes in SSB during this period were to a large extent due to deviations in weight at age.

Sprat recruitment (age-group 1) as determined by both methods was rather similar in all years considered. The areadisaggregated MSVPA revealed in general slightly higher values, with the exception of recent years (Fig. 9).

\section{Discussion}

The results of the area-disaggregated MSVPA runs performed here revealed distinct trends in population abundance, spawning biomass, recruitment, and predation mortalities of cod and sprat in different areas of the Central Baltic. These results were in general similar to time trends in population sizes of cod and sprat as estimated by standard assessments, research surveys utilised for tuning of the MSVPA runs, as well as independent estimates of stock abundance. The application of the area-disaggregated MSVPA was inconclusive for Baltic herring stocks due to timing and area coverage of surveys, complexity of stock structure, and migratory behaviour. Hence, due to the limited amount of other suitable data series on herring abundance, a conclusive validation of distribution of the stock appears at present to be impossible. The area-disaggregated MSVPA does, however, capture the temporal dynamics of the Baltic herring population as estimated by the standard assessment.

A number of data-related and methodological problems impact upon the utility of the present approach for cod and sprat. For example, the newly compiled catch at age data for cod and sprat (ICES 1997a) showed considerable fluctuations in some age-groups, quarters, and years. High variability in the catch in numbers of the last age-group of cod caused problems in tuning the terminal fishing mortality values. For sprat, tuning of the last year in the time series was problematic in Subdivisions 25 and 26 due to trends in fishing mortality at age as well as changes in the exploitation 
Fig. 8. SSB derived by area-disaggregated MSVPA and standard stock assessments (XSA) (both at the beginning of the year) of (a) cod, (b) herring, and (c) sprat (solid circles, MSVPA; open circles, XSA for standard assessment areas; triangles (Fig. 8b), XSA Subdivisions 25-28). See text for a detailed description of standard assessment areas.

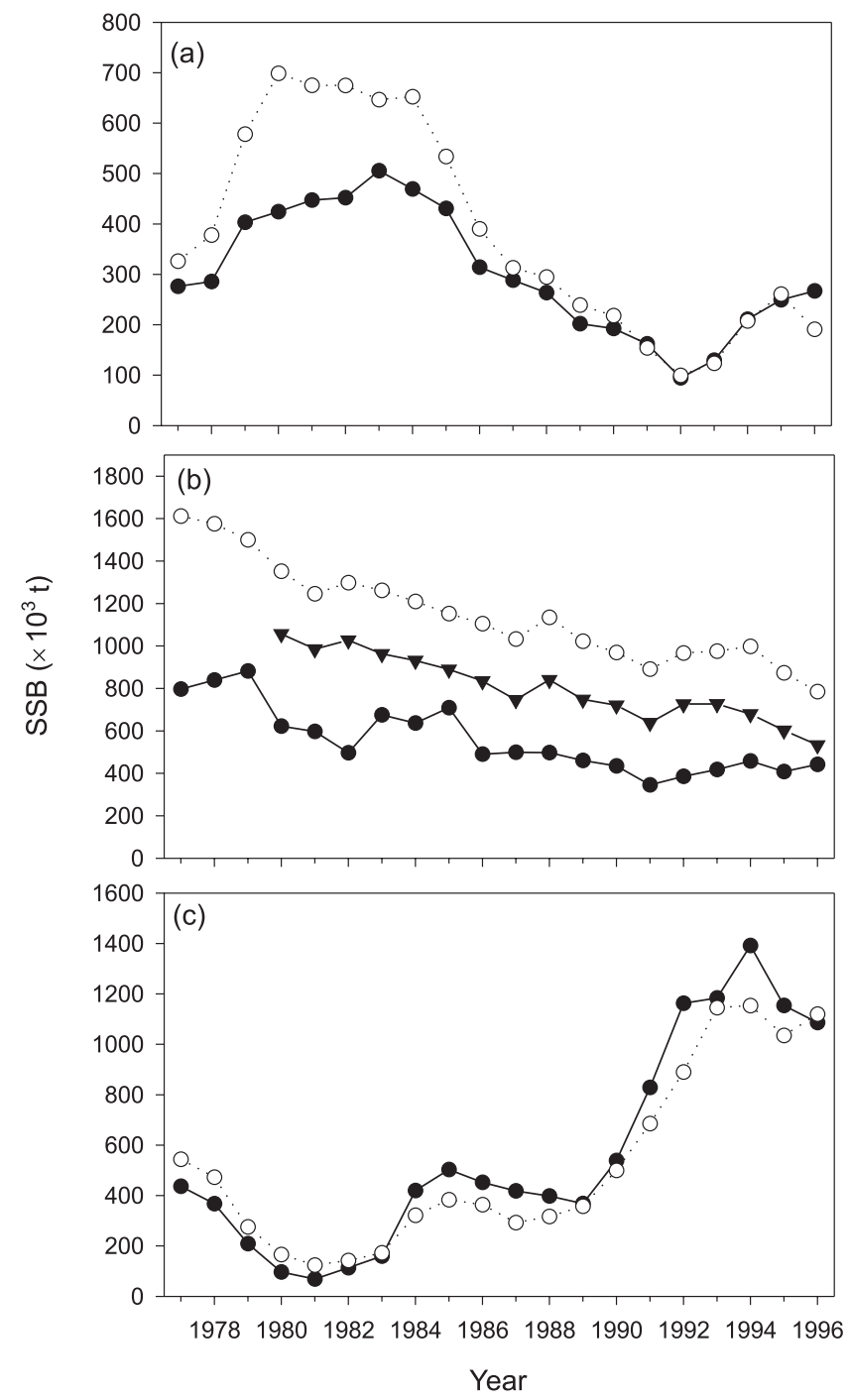

pattern (ICES 1998) caused by the commencement of a largescale reduction fishery.

The virtual population analysis technique assumes that catch at age data are exact input data, which due to several reasons is seldom the case. The present analysis covers a time period with well-established reporting systems in the Baltic introduced in the mid-1970s. The data compilation procedure utilising information submitted by the responsible national laboratories is described in detail in ICES (1997a, 1999a). However, discarding and misreporting take place in Baltic cod and are not accounted for in the present catch at age data. The estimated discards of age-group 1-2 in 1998 and 1999 amounted to 17 and 4\%, 9 and $2 \%$, and 3 and $2 \%$ of the total catch in numbers in Subdivisions 25, 26, and 28, respectively (ICES 2000). These preliminary data indicate considerable interannual variability in discards and a poten-
Fig. 9. Recruitment derived by area-disaggregated MSVPA and standard stock assessments (XSA) (beginning of the year) of (a) cod, (b) herring, and (c) sprat (solid circles, MSVPA; open circles, XSA for standard assessment areas; triangles (Fig. 9b), XSA Subdivisions 25-28). See text for a detailed description of standard assessment areas.
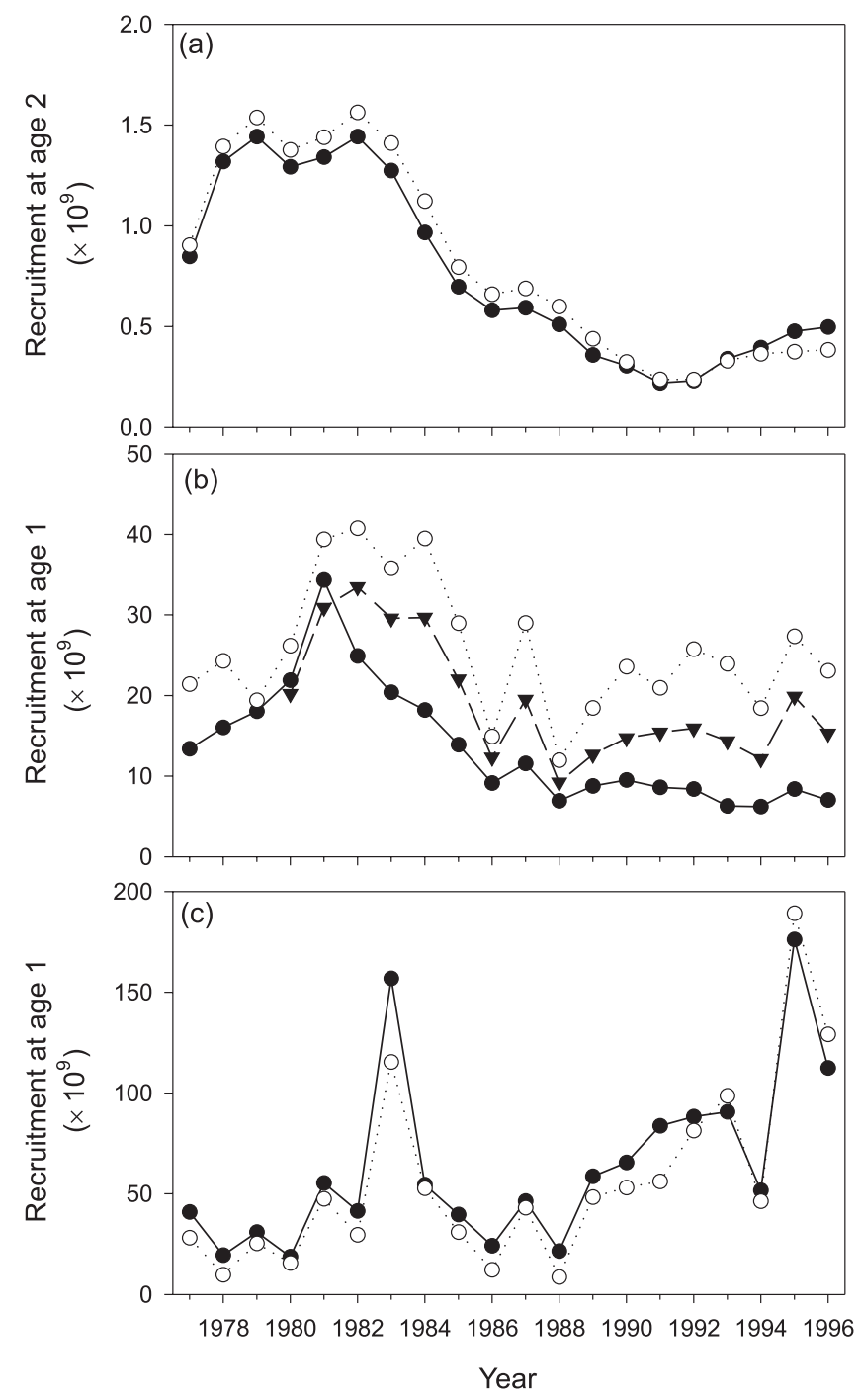

tial bias of recruitment estimates in years of intensive discarding. Misreporting in the cod fishery has been identified by ICES (1997b) especially for the period 1992-1994 with restrictive fisheries management measures enforced. Misreporting is partly accounted for by national catch estimates treated in the assessment as unallocated catches according to subdivision. However, for the above period, a considerable underestimation of the catch may have nevertheless occurred, affecting the spawning stock size estimation in 1991-1994 and recruitment of the 1990-1992 year-classes. Another source of bias is errors in age reading of Baltic cod otoliths (Bagge et al. 1994), with deviations in estimated age of 1-2 years between different countries commonly occurring (ICES 2000). This affects especially the estimation of yearclass strength and its interannual variability.

Migration between different areas of the Central Baltic is 
expected to have an impact on the area-disaggregated MSVPA results for all stocks. As stated by ICES (1999a), explicit inclusion of the migration process into the MSVPA context is difficult, and at present, no adequate methodology is available. Reliable migration rates are missing for all stocks under consideration, and databases required for the implementation of statistically based spatial multispecies models, e.g., BORMICON (Stefánsson and Pálsson 1998), are not readily available. Even with these databases at hand, however, conflicting output trends depending on considered data sources might also be encountered, as recently demonstrated for the BORMICON application in the Icelandic system (Stefánsson 1998). At present, the only feasible way of resolving spatial distribution in the Baltic is to run a suite of independent MSVPAs for the different subareas, as performed in this study. Following this approach, migration is accounted for by fluctuations in the catch at age data only.

The validation of the area-disaggregated MSVPA results provided several indications of migratory behaviour by cod. The recruitment of cod determined in Subdivisions 26 and 28 , in the absence of any reproductive volume, indicates an introduction of recruits from the neighbouring Subdivision 25 , the only spawning area at present with hydrographic conditions conducive to egg survival (MacKenzie et al. 2000). Migration between basins was also evidenced from the comparison of relative distribution pattern of age-groups 1 and 2 derived by area-disaggregated MSVPA runs and trawl surveys. The results suggest that most of the recruitment to the eastern spawning areas in the last 10 years has originated in Subdivision 25, as concluded by Bagge and Thurow (1993), juvenile pelagic stages originating in Subdivision 25 being transported to southeastern areas of the Central Baltic and expanding northwards into the Gotland Basin during their second and third years of life. Furthermore, from the comparison of area-disaggregated MSVPA derived relative distributions of adult cod and trawl survey results, it is clear that a substantial part of the adult stock returns to spawn in the Bornholm Basin. Such a spawning migration is confirmed by historical tagging data (Netzel 1974) and catchper-unit-effort data from commercial fisheries (Lablaika and Lishev 1961). Cod tagged in the vicinity of the Bornholm Basin behaved rather stationary (Bagge et al. 1974). As a consequence, stock numbers at age 1 and 2 in Subdivision 25 are always overestimated by the area-disaggregated MSVPA. This is a problem in modelling cannibalism, as recruits originating from Subdivision 25 growing up in Subdivision 26 are preyed upon in the model by the wrong stock component. However, the adult cod population size was calculated to be of the same order of magnitude in Subdivisions 25 and 26, and thus, it is not expected that predation mortalities are seriously biased.

As a consequence of the observed migration patterns of cod, the application of area-specific results in stock recruitment models depends critically on the behaviour of recruits growing up in Subdivisions 26 and 28 after reaching sexual maturity. If they return to their original spawning ground, independent of the hydrographic situation, no significant influence on area-specific stock-recruitment relationships is to be expected. If, however, favourable hydrographic conditions in eastern basins result in a spawning behaviour close to their nursery areas or if unfavourable spawning conditions force the mature stock components originating from Subdivisions 26 and 28 to migrate to the Bornholm Basin, biased relationships are likely. The first behaviour will result in a gain of recruits in Subdivisions 26 and 28 under favourable oxygen conditions, whereas the latter will lead to a corresponding gain of adults in Subdivision 25 during stagnation periods. In the area-disaggregated MSVPA model, these cod entering the fishery will increase not only the estimated adult stock size in the subdivision but also the estimates of recruitment some years back in time. Although spawning migrations into the Bornholm Basin occur regularly, also in years of favourable environmental spawning conditions in eastern spawning areas (Netzel 1974), the intensity of the spawning migration has been related to environmental conditions (Lablaika and Lishev 1961). Thus, it is likely that both described scenarios occur. Consequently, a certain impact of variable spawning migrations on the population estimates derived by the areadisaggregated MSVPA runs has to be expected. Additionally, separation into subdivisions is not the most appropriate way to distinguish between different spawning populations of cod, as Subdivision 26 contains, in addition to the Gdansk Deep, the southern tip of the Gotland Basin and thus represents to a certain extent a mixture of two spawning stock components.

For sprat, the contribution of Subdivision 25 to the combined stock in the Central Baltic was found to be considerably greater in the MSVPA output than in the SeptemberOctober hydroacoustic surveys. However, hydroacoustic surveys in May-June showed highest sprat concentrations in the Bornholm Basin, thus confirming the distribution pattern obtained by the area-disaggregated MSVPA runs. This indicates a different distribution of sprat during spawning and feeding periods, potentially caused by migrations between subdivisions, a process that is at present not sufficiently resolved (see Aro 1989; Parmanne et al. 1994). A potential redistribution of the sprat spawning stock during feeding will have an effect on the SSB and recruitment estimated by the area-disaggregated MSVPA runs for the different subdivisions. However, a major part of the catch is obtained during the first half of the year in a fishery directed to prespawning and spawning concentrations (ICES 1999b). Hence, the relative distributions derived by the area-disaggregated MSVPA runs and hydroacoustic surveys at spawning time are well in line. Consequently, the effect of migratory behaviour on SSB estimates should be of limited importance.

In summary, the area-disaggregated MSVPA approach presented here has, through comparison with existing data sets, successfully resolved the basin-specific stock dynamics of cod and sprat in the Central Baltic Sea. This result allows the application of the area-disaggregated MSVPA to spatially resolve the SSB of the different spawning basins, thereby allowing the utilisation of area-specific reproductive success in recruitment modelling of these stocks (Köster et al. 2001). This is a key issue in the management of Baltic fish stocks.

Utilisation of basin-specific spawning stock sizes and structures as a measure of the stock's reproductive effort in different spawning areas is to a certain degree affected by migration. However, as the fishery on cod and sprat tradi- 
tionally focuses on prespawning and spawning concentrations, the area-disaggregated MSVPA derived results are believed to give an improved and extended estimate of the time series of stock size, structure, and distribution when compared with available trawl and hydroacoustic survey estimates. Furthermore, the results obtained during this exercise, in conjunction with the available survey information, may be utilised to estimate migration rates between different subareas, an issue affecting the ability of the stocks to optimise suitable spawning habitats when available.

\section{Acknowledgements}

All participants of the ICES Study Group on Multispecies Model Implementation in the Baltic have contributed their experience, knowledge, and results to the present study and this is gratefully acknowledged. In particular, the support by Morten Vinther with respect to program and data handling was of great help. The authors are grateful to Dr. Odd Nakken and one anonymous referee for their careful, thorough, and helpful comments. The present study has been carried out with financial support from the Commission of the European Communities, Agriculture and Fisheries (AIR and FAIR), specific RTD programmes CT94-1226 CORE and CT98-3959 STORE. This paper does not necessarily reflect the views of the Commission and in no way anticipates the Commission's future policy in this area.

\section{References}

Aps, R., Falk, U., and Oeberst, R. 1981. Morphological variability of otolith growth zones in the Baltic sprat. Fisch.-Forsch. 19(2): 27-30.

Aro, E. 1989. A review of fish migration patterns in the Baltic. Rapp. P.-v. Réun. Cons. Int. Explor. Mer, 190: 72-96.

Bagge, O., and Thurow, F. 1993. The Baltic cod stock: fluctuations and possible causes. ICES Mar. Sci. Symp. 198: 254-268.

Bagge, O., Tiews, K., Lamb, F., and Otterlind, G. 1974. German, Swedish and Danish cod tagging experiments in the Baltic 196869. Rapp. P.-v. Réun. Cons. Int. Explor. Mer, 166: 22-39.

Bagge, O., Thurow, F., Steffensen, E., and Bay, J. 1994. The Baltic cod. Dana, 10: 1-28.

Hinrichsen, H.-H., St. John, M.A., Aro, E., Grønkjær, P., and Voss, R. 2001. Testing the larval drift hypothesis in the Baltic Sea: retention vs. dispersion due to the influence of wind driven circulation. ICES Mar. Sci. Symp. 209. In press.

ICES. 1997a. Report of the Study Group on Multispecies Model Implementation in the Baltic. ICES CM 1997/J:2.

ICES. 1997b. Report of the Baltic Fisheries Assessment Working Group. ICES CM 1997/Assess:12.

ICES. 1998. Report of the Baltic Fisheries Assessment Working Group. ICES CM 1998/ACFM:16.

ICES. 1999a. Report of the Study Group on Multispecies Model Implementation in the Baltic. ICES CM 1999/H:5.

ICES. 1999b. Report of the Baltic Fisheries Assessment Working Group. ICES CM 1999/ACFM:15.

ICES. 2000. Report of the Baltic Fisheries Assessment Working Group. ICES CM 2000/ACFM:14.

Köster, F.W., and Möllmann, C. 2000. Trophodynamic control by clupeid predators on recruitment success in Baltic cod? ICES J. Mar. Sci. 57: 310-323.
Köster, F.W., Hinrichsen, H.-H., St. John, M.A., Schnack, D., MacKenzie, B.R., Tomkiewicz, J., and Plikshs, M. 2001. Developing Baltic cod recruitment models. II. Incorporation of environmental variability and species interaction. Can. J. Fish. Aquat. Sci. 58: $1535-1557$.

Lablaika, I.N., and Lishev, M.N. 1961. Possibilities of forecasting the distribution of stock and efficiency of fishing for Baltic cod during pre-spawning and spawning periods. ICES CM 1961/ Baltic/Belt Sea Comm. 90.

MacKenzie, B.R., Hinrichsen, H.-H., Plikshs, M., Wieland, K., and Zezera, A.S. 2000. Quantifying environmental heterogeneity: habitat size necessary for successful development of cod Gadus morhua eggs in the Baltic Sea. Mar. Ecol. Prog. Ser. 193: 143-156.

Magnusson, K.G. 1995. An overview of the multispecies VPA theory and applications. Rev. Fish Biol. Fish. 5: 195-212.

Netzel, J. 1974. Polish cod tagging experiments in the Baltic in 1969 and 1970. Rapp. P.-v. Réun. Cons. Int. Explor. Mer, 166: 22-39.

Neuenfeldt, S., and Köster, F.W. 2000. Trophodynamic control on recruitment success in Baltic cod: the influence of cannibalism. ICES J. Mar Sci. 57: 300-309.

Nissling, A., and Westin, L. 1991. Egg buoyancy of Baltic cod (Gadus morhua) and its implication for cod stock fluctuations in the Baltic. Mar. Biol. 111: 33-35.

Ojaveer, E. 1981. Fish fauna of the Baltic. In The Baltic Sea. Edited by A. Voipio. Elsevier Oceanogr. Ser. 30. Elsevier Scientific Publishing Co., Amsterdam, Oxford, New York. pp. 275-292.

Ojaveer, E. 1989. Population structure of pelagic fishes in the Baltic. Rapp. P.-v. Réun. Cons. Int. Explor. Mer, 190: 17-21.

Ojaveer, E., and Elken, J. 1995. On regional subunits in the ecosystem of the Baltic Sea. Proceedings of the 14th Baltic Marine Biologists Symposium, Paernu, Estonia. Eastonian Academy Publishers, Tallinn. pp. 22-23.

Parmanne, R., Rechlin, O., and Sjöstrand, B. 1994. Status and future of herring and sprat stocks in the Baltic Sea. Dana, 10: 29-59.

Pope, J.G. 1991. The ICES Multispecies Assessment Working Group: evolution, insights, and future problems. ICES Mar. Sci. Symp. 193: $22-32$.

Shepherd, J.G. 1999. Extended survivors analysis: an improved method for the analysis of catch-at-age data and abundance indices. ICES J. Mar. Sci. 56: 584-591.

Sjöstrand, B. 1989. Assessment reviews: exploited pelagic fish stocks in the Baltic. Rapp. P.-v. Réun. Cons. Int. Explor. Mer, 190: 235252.

Sparholt, H. 1991. Multispecies assessment of Baltic fish. ICES Mar. Sci. Symp. 193: 64-79.

Sparholt, H. 1994. Fish species interactions in the Baltic Sea. Dana, 10: $131-162$.

Sparholt, H., and Tomkiewicz, J. 2000. A robust method to compile trawl survey data applied in assessment of Central Baltic cod. Arch. Fish. Mar. Res. 48: 125-151.

Sparre, P. 1991. Introduction to multispecies virtual population analysis. ICES Mar. Sci. Symp. 193: 12-21.

Stefánsson, G. 1998. Comparing different information sources in a multispecies context. Proceedings of the Symposium on Fishery Stock Assessment Models. Alaska Sea Grant College Program Rep. 98-01. University of Alaska, Fairbanks. pp. 741-758.

Stefánsson, G., and Pálsson, O.K. 1998. A framework for multispecies modelling of boreal systems. Rev. Fish Biol. Fish. 8: 101-104.

Stokes, T.K. 1992. An overview of the North Sea multispecies modelling work in ICES. S. Afr. J. Mar. Sci. 12: 1051-1060. 
Tomkiewicz, J., Eriksson, M., Baranova, T., Feldman, V., and Müller, H. 1997. Maturity ogives and sex ratios for Baltic cod: establishment of a database and time series. ICES CM 1997/CC:20.

Uzars, D., Plikshs, M., Grauman, G., Kalejs, M., and Baranova, T. 1991. Cod distribution and spawning in the Gotland Basin in the 1980's. ICES CM 1991/J:5.

Voss, R., Hinrichsen, H.-H., and St. John, M.A. 1999. Variations in the drift of larval cod (Gadus morhua L.) in the Baltic Sea: combining field observations and modelling. Fish. Oceanogr. 8: 199-211.

Wieland, K., Waller, U., and Schnack, D. 1994. Development of Baltic cod eggs at different levels of temperature and oxygen content. Dana, 10: 163-177.

\section{Appendix}

Table A1. SSB (second quarter), recruitment (age-group 1, first quarter), and stock size (cod: age-group 2+, first quarter; herring and sprat: age-group 1+, fourth quarter) in different subdivisions (SD) of the Central Baltic determined from area-disaggregated MSVPA.

\begin{tabular}{|c|c|c|c|c|c|c|c|c|c|}
\hline \multirow[b]{2}{*}{ Year } & \multicolumn{3}{|l|}{ Cod } & \multicolumn{3}{|l|}{ Herring } & \multicolumn{3}{|l|}{ Sprat } \\
\hline & SD 25 & SD 26 & SD 28 & SD 25 & SD 26 & SD 28 & SD 25 & SD 26 & SD 28 \\
\hline \multicolumn{10}{|c|}{ SSB (kt) } \\
\hline 1977 & 92 & 96 & 39 & 387 & 290 & 120 & 93 & 196 & 148 \\
\hline 1978 & 96 & 110 & 63 & 384 & 325 & 131 & 82 & 169 & 116 \\
\hline 1979 & 105 & 141 & 86 & 376 & 333 & 173 & 55 & 91 & 63 \\
\hline 1980 & 110 & 181 & 72 & 343 & 199 & 81 & 26 & 45 & 26 \\
\hline 1981 & 144 & 158 & 56 & 293 & 200 & 104 & 19 & 30 & 19 \\
\hline 1982 & 135 & 148 & 65 & 261 & 207 & 63 & 29 & 50 & 34 \\
\hline 1983 & 163 & 156 & 67 & 339 & 230 & 71 & 69 & 61 & 29 \\
\hline 1984 & 118 & 131 & 62 & 312 & 183 & 52 & 161 & 195 & 64 \\
\hline 1985 & 116 & 115 & 54 & 277 & 160 & 83 & 218 & 219 & 66 \\
\hline 1986 & 87 & 70 & 39 & 273 & 137 & 81 & 223 & 181 & 48 \\
\hline 1987 & 87 & 73 & 30 & 227 & 141 & 131 & 210 & 164 & 45 \\
\hline 1988 & 88 & 67 & 21 & 225 & 113 & 159 & 199 & 136 & 63 \\
\hline 1989 & 76 & 47 & 13 & 206 & 119 & 136 & 164 & 129 & 75 \\
\hline 1990 & 79 & 47 & 8 & 195 & 100 & 139 & 239 & 178 & 121 \\
\hline 1991 & 54 & 32 & 7 & 159 & 84 & 102 & 330 & 289 & 210 \\
\hline 1992 & 41 & 37 & 3 & 170 & 113 & 103 & 469 & 471 & 223 \\
\hline 1993 & 88 & 53 & 5 & 164 & 117 & 138 & 585 & 363 & 236 \\
\hline 1994 & 116 & 61 & 5 & 198 & 111 & 149 & 569 & 512 & 310 \\
\hline 1995 & 110 & 75 & 6 & 187 & 91 & 131 & 421 & 451 & 282 \\
\hline 1996 & 113 & 118 & 4 & 179 & 75 & 189 & 417 & 413 & 256 \\
\hline \multicolumn{10}{|c|}{ Recruitment (millions) } \\
\hline 1977 & 418 & 486 & 242 & 5532 & 5416 & 2934 & 10661 & 20896 & 9387 \\
\hline 1978 & 327 & 375 & 159 & 6332 & 4801 & 4162 & 4910 & 8674 & 5963 \\
\hline 1979 & 321 & 316 & 147 & 3874 & 6860 & 5955 & 4686 & 21695 & 4561 \\
\hline 1980 & 465 & 611 & 235 & 4930 & 6980 & 6991 & 3915 & 9565 & 5249 \\
\hline 1981 & 500 & 491 & 240 & 9756 & 12341 & 6485 & 10137 & 27512 & 17721 \\
\hline 1982 & 296 & 281 & 170 & 6774 & 8166 & 9928 & 20950 & 14309 & 6191 \\
\hline 1983 & 167 & 173 & 128 & 6558 & 5730 & 8156 & 38500 & 82162 & 36231 \\
\hline 1984 & 146 & 123 & 85 & 5010 & 4385 & 8797 & 27486 & 16801 & 10174 \\
\hline 1985 & 172 & 128 & 63 & 4814 & 4086 & 4953 & 19531 & 14208 & 5930 \\
\hline 1986 & 243 & 127 & 67 & 3594 & 2502 & 3036 & 14144 & 6939 & 3124 \\
\hline 1987 & 145 & 75 & 26 & 3318 & 2015 & 6245 & 20239 & 15555 & 10562 \\
\hline 1988 & 101 & 40 & 13 & 3562 & 1757 & 1616 & 15402 & 3225 & 2924 \\
\hline 1989 & 129 & 50 & 18 & 4645 & 1687 & 2436 & 30460 & 15867 & 12326 \\
\hline 1990 & 65 & 38 & 6 & 3756 & 2023 & 3734 & 26584 & 25094 & 13783 \\
\hline 1991 & 114 & 53 & 7 & 3237 & 1921 & 3458 & 34828 & 36335 & 12566 \\
\hline 1992 & 160 & 70 & 7 & 3647 & 2259 & 2479 & 36522 & 36327 & 15408 \\
\hline 1993 & 112 & 89 & 4 & 2846 & 1631 & 1812 & 34879 & 34823 & 20968 \\
\hline 1994 & 127 & 170 & 4 & 2879 & 1567 & 1776 & 25023 & 20299 & 6382 \\
\hline 1995 & 160 & 87 & 6 & 3788 & 2171 & 2442 & 80169 & 68414 & 27541 \\
\hline 1996 & 168 & 28 & 1 & 3498 & 1532 & 2004 & 54916 & 38687 & 18811 \\
\hline
\end{tabular}


Table A1 (concluded).

\begin{tabular}{|c|c|c|c|c|c|c|c|c|c|}
\hline \multirow[b]{2}{*}{ Year } & \multicolumn{3}{|l|}{ Cod } & \multicolumn{3}{|l|}{$\underline{\text { Herring }}$} & \multicolumn{3}{|l|}{ Sprat } \\
\hline & SD 25 & SD 26 & SD 28 & SD 25 & SD 26 & SD 28 & SD 25 & SD 26 & SD 28 \\
\hline \multicolumn{10}{|c|}{$\overline{\text { Stock size (millions) }}$} \\
\hline 1977 & 311 & 363 & 174 & 7698 & 6227 & 4959 & 8563 & 22937 & 14762 \\
\hline 1978 & 475 & 555 & 289 & 8049 & 5889 & 5120 & 5219 & 11290 & 7533 \\
\hline 1979 & 541 & 606 & 295 & 6214 & 5466 & 5050 & 3498 & 9434 & 3434 \\
\hline 1980 & 470 & 579 & 244 & 5556 & 4625 & 5554 & 2255 & 4182 & 2669 \\
\hline 1981 & 542 & 567 & 232 & 7415 & 7591 & 5328 & 4393 & 11982 & 6153 \\
\hline 1982 & 629 & 554 & 259 & 7483 & 8563 & 6807 & 10059 & 8490 & 3846 \\
\hline 1983 & 565 & 478 & 231 & 7145 & 11147 & 6238 & 19794 & 41654 & 13065 \\
\hline 1984 & 409 & 373 & 185 & 7064 & 9365 & 7133 & 25338 & 29829 & 8948 \\
\hline 1985 & 292 & 262 & 143 & 6979 & 4359 & 6864 & 24358 & 22926 & 7415 \\
\hline 1986 & 276 & 197 & 107 & 6044 & 3620 & 5920 & 20885 & 16295 & 4977 \\
\hline 1987 & 324 & 179 & 90 & 5685 & 3347 & 8595 & 24599 & 18540 & 10261 \\
\hline 1988 & 304 & 144 & 62 & 5122 & 2894 & 6948 & 17559 & 11545 & 8073 \\
\hline 1989 & 232 & 94 & 33 & 5895 & 2850 & 6080 & 25254 & 18855 & 14349 \\
\hline 1990 & 193 & 86 & 26 & 5840 & 3266 & 7087 & 32237 & 29792 & 21231 \\
\hline 1991 & 143 & 63 & 15 & 6062 & 3643 & 7251 & 46885 & 49694 & 25551 \\
\hline 1992 & 140 & 82 & 10 & 6871 & 4300 & 6458 & 56793 & 62174 & 28336 \\
\hline 1993 & 215 & 113 & 12 & 6617 & 3872 & 5843 & 61041 & 67892 & 39274 \\
\hline 1994 & 239 & 145 & 11 & 6210 & 3405 & 5628 & 52004 & 55477 & 33411 \\
\hline 1995 & 239 & 228 & 10 & 6454 & 3314 & 6004 & 81700 & 77071 & 46772 \\
\hline 1996 & 259 & 228 & 10 & 6391 & 2718 & 5805 & 76122 & 59937 & 44349 \\
\hline
\end{tabular}

Table A2. Indices of stock sizes for different subdivisions (SD): cod age-group 2+ from the Baltic international trawl survey in February-March and age-group 3+ from the Latvian bottom trawl survey in January (left column) and November-December (right column, no. $\cdot \mathrm{h}^{-1}$ ) and herring and sprat age-group 1+ from international hydroacoustic surveys in September-October (millions).

\begin{tabular}{|c|c|c|c|c|c|c|c|c|c|c|c|c|c|}
\hline \multirow[b]{2}{*}{ Year } & \multicolumn{3}{|c|}{ Cod age-group 2+ } & \multicolumn{4}{|c|}{ Cod age-group 3+ } & \multicolumn{3}{|c|}{ Herring } & \multicolumn{3}{|l|}{ Sprat } \\
\hline & SD 25 & SD 26 & SD 28 & SD 26 & SD 26 & SD 28 & SD 28 & SD 25 & SD 26 & SD 28 & SD 25 & SD 26 & SD 28 \\
\hline 1977 & & & & 71 & & 285 & & & & & & & \\
\hline 1979 & & & & 2830 & & 1068 & & & & & & & \\
\hline 1980 & 663 & & & & & & & & & & & & \\
\hline 1981 & 1290 & 1361 & & & & 908 & 908 & & & & & & \\
\hline 1984 & 891 & 786 & 1053 & 3383 & 734 & 1428 & 617 & 4156 & 2881 & 9429 & 7395 & 22405 & 5800 \\
\hline 1985 & 884 & 658 & 957 & 1232 & 288 & 154 & 132 & 2798 & 3988 & 9350 & 12227 & 9394 & 2178 \\
\hline 1986 & 365 & 491 & 539 & & 38 & 170 & 83 & 7696 & 8547 & 7977 & 5647 & 7792 & 3878 \\
\hline 1987 & 771 & 694 & 703 & 454 & & 42 & 8 & 3761 & 5172 & 9283 & 4455 & 6120 & 9048 \\
\hline 1988 & 479 & 590 & 574 & 332 & 117 & 253 & 65 & 4725 & 6738 & 6609 & 4917 & 3408 & 3155 \\
\hline 1993 & 458 & 172 & 49 & & & & & & & & & & \\
\hline 1994 & 706 & 293 & 68 & & & & & 9037 & 9399 & 16597 & 13983 & 35297 & 24849 \\
\hline 1995 & 379 & 928 & 99 & & & & & 4759 & 7421 & 7985 & 18155 & 50214 & 128170 \\
\hline 1996 & 489 & 603 & 66 & & & & & 7750 & 4937 & 12821 & 24594 & 62374 & 117462 \\
\hline
\end{tabular}

Note: An empty cell indicates that a reliable survey was not conducted during that period. 
Table A3. Recruitment of cod, herring, and sprat (age-group 1) derived from the Baltic international bottom trawl surveys $\left(\right.$ no. $\cdot \mathrm{h}^{-1}$ ) and the international hydroacoustic survey (millions).

\begin{tabular}{|c|c|c|c|c|c|c|c|c|c|}
\hline \multirow[b]{2}{*}{ Year } & \multicolumn{3}{|l|}{ Cod } & \multicolumn{3}{|l|}{ Herring } & \multicolumn{3}{|l|}{$\underline{\text { Sprat }}$} \\
\hline & SD 25 & SD 26 & SD 28 & SD 25 & SD 26 & SD 28 & SD 25 & SD 26 & SD 28 \\
\hline 1980 & 10.3 & & & & & & & & \\
\hline 1981 & 309.7 & 3294.6 & & & & & & & \\
\hline 1982 & 26.5 & 816.2 & 187.5 & 768 & 1146 & 991 & 361 & 2832 & 1037 \\
\hline 1983 & 36.8 & 52.2 & 43.8 & 966 & 1142 & 510 & 7166 & 15569 & 8610 \\
\hline 1984 & 36.8 & 309.1 & 15.4 & 654 & 466 & 3315 & 581 & 10979 & 1140 \\
\hline 1985 & 15.0 & 129.5 & 11.6 & 886 & 713 & 743 & 2036 & 1415 & 458 \\
\hline 1986 & 11.9 & 6.8 & 5.5 & 2224 & 874 & 261 & 58 & 1127 & 59 \\
\hline 1987 & 47.7 & 163.8 & 6.5 & 723 & 1023 & 1983 & 306 & 4002 & 5925 \\
\hline 1988 & 7.7 & 30.6 & 9.2 & 552 & 510 & 171 & 92 & 44 & 22 \\
\hline 1989 & 6.4 & 202.6 & 10.6 & 992 & 745 & 1230 & 1010 & 23345 & 7842 \\
\hline 1990 & 7.9 & 113.9 & 8.7 & 940 & 1422 & 1926 & 339 & 3194 & 4576 \\
\hline 1991 & 6.0 & 26.1 & 0.3 & 918 & 1762 & 1018 & 2665 & 26985 & 9254 \\
\hline 1992 & 15.7 & 10.7 & 0.1 & 633 & 1998 & 456 & 636 & 16031 & 12222 \\
\hline 1993 & 28.7 & 78.8 & 2.3 & & & & & & \\
\hline 1994 & 71.1 & 227.1 & 1.7 & 536 & 827 & 277 & 245 & 8955 & 473 \\
\hline 1995 & 18.4 & 310.2 & 0.1 & 781 & 952 & 459 & 8276 & 31382 & 75143 \\
\hline 1996 & 2.3 & 41.7 & 0.0 & 373 & 506 & 330 & 3674 & 24698 & 29674 \\
\hline
\end{tabular}

Note: An empty cell indicates that a reliable survey was not conducted that year. 